Final Report \title{
Synthesis study on The use of concrete Recycled pavements
and Building Rubble In The Indiana Highway system
}

\author{
by \\ Thomas T. Burke \\ Menashi D. Cohen \\ Charles F. Scholer
}

Joint Highway Research Project

Project No.: $\mathrm{C}-36-50 \mathrm{~m}$

File No.: 6-19-13
Prepared as Part of an Investigation conducted by the
Joint Highway Research Project
Engineering Experiment station
Purdue University

\author{
In Cooperation with the \\ Indiana Department of Transportation \\ and the \\ U.S. Department of Transportation \\ Federal Highway Administration
}

The contents of this document reflect the views of the authors who are responsible for the facts and accuracy of the data presented herein. The contents do not necessarily reflect the official views or policies of the Federal Highway Administration. This document does not constitute a standard, specifications, or regulations.

\author{
School of Civil Engineering \\ Purdue University \\ West Lafayette, Indiana 47907
}

September 1992 


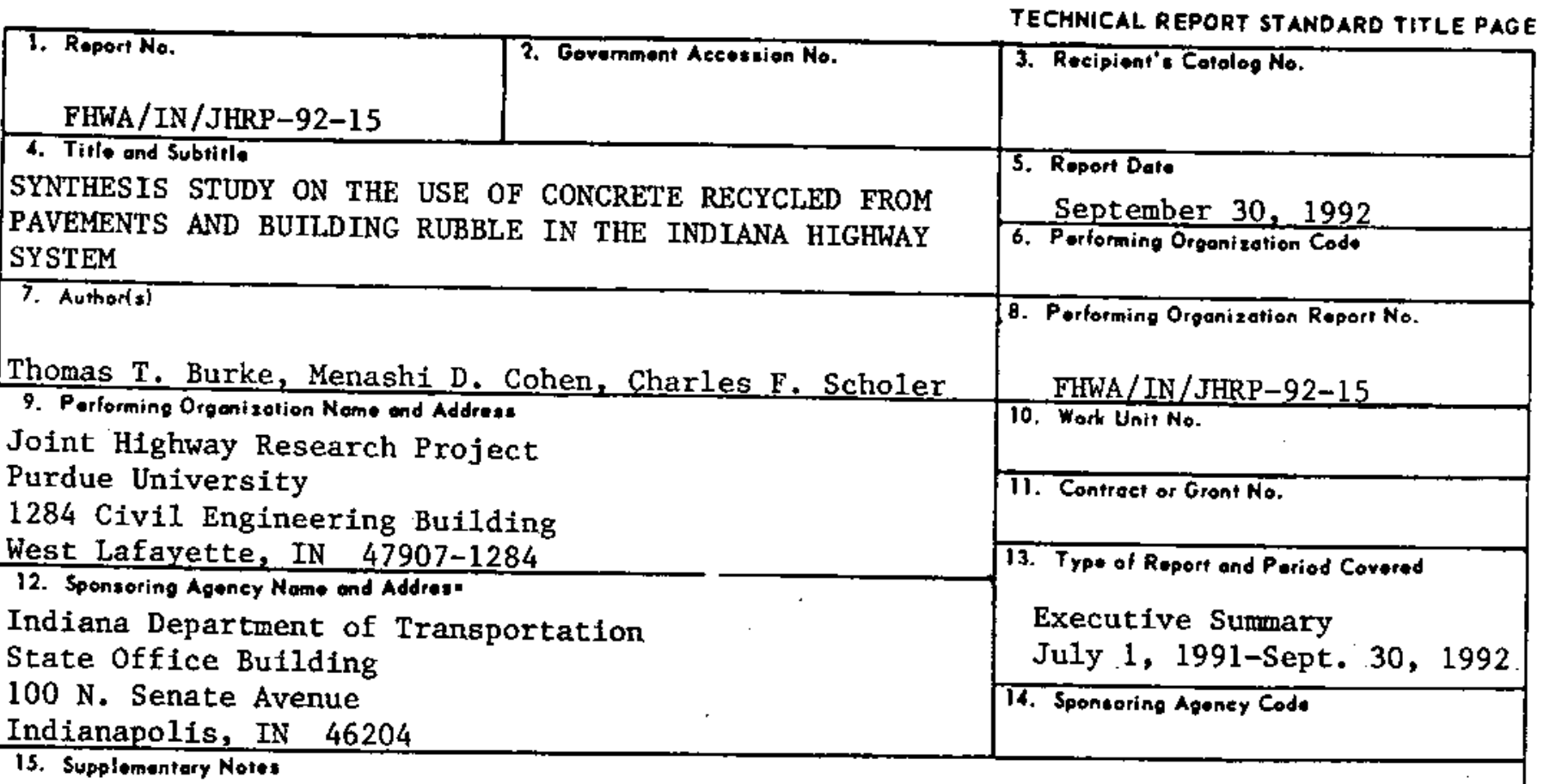

16. Abstroct The demolition of bufldings and highway pavements in the State of Indiana generates a considerable amount of waste materials. The disposal of these materials causes strain on the existing landfills which are rapidiy approaching their full capacity. This study is a synthesis of the information on the use of concrete recycled from pavements and building rubble for use in the Indiana highway system. Test results have shown that recycled pavement concrete made chiefly from broken-up and crushed old concrete aggregate is as good as concrete made from virgin aggregate, and sometimes better. The aggregates made from recycled concrete can be used in other applications besides structural pavement. These include shoulder pavement, road surfacing, fill soll stabilizer, pavement base, sub-base material, and econocrete as well as several other applications which are still being tested. The use of recycled fine aggregates should be carefully monitored and should not be used for the development of medium to high-strength concrete. Fines should also not be used in the subbase, embankment under abutments, and locations surrounding filters. Economic considerations are the primary reasons for recycling the old portland cement concrete as aggregate in new portland cement concrete pavements, although environmental benefits of ten are derived as well and may become more important in the future. After analyzing other states findings and conclusions, it is recommended that the Indiana Department of Transportation continue recycling portland cement concrete from pavements and proceed with the implementation of a program for recycling concrete from buildings rubbles.

\section{Kay Words}

Recycled concrete, Building demolition, Pavements, Building rubble, Risk assessment, Liability, Aggregate, Economics, Environmental
18. Distribution Stotoment

No restriction. This document is available to the public through the National Technical Information Service, Virginia 22161
19. Securtty Clesell. (of this report)

Unclassified
20. Securlty Clatelf. (of thit peop)

Unclassified

Form Dot F 1700.7 (6-s) 


\section{ACRNOTLEDGEMENTS}

Thanks are extended to the advisory committee members, especially Mr. R. Smutzer, Mr. Y. Yiang, and Mr. C. Alley for their suggestions and helpful comments in finalizing the report; to $\mathrm{Mr}$. Ken Hoover and his office for sending the survey questionnaire to the United States highway agencies; to all United States highway agencies who promptly responded to the survey questionnaire of this study; to the state highway agencies of Connecticut, Illinois, Iowa, Michigan, Minnesota, Nebraska, New Jersey, New York, and Wyoming for providing supplementary information; to Keith Papanicolas for obtaining the numerous articles that had to be reviewed; and to Ms. Karen Ferguson for editing the report.

Financial support provided by the INDOT and the Federal Highway Administration through the Joint Highway Research Project, School of Civil Engineering, Purdue University, West Lafayette, Indiana, is thankfully acknowledged. 


\title{
Synthesis study on The סBe of Concrete Recycled Pavements And Building Rubble In The Indlana righway system
}

\author{
Implementation. Report
}

This report is a synthesis of the information on the use of concrete recycled from pavements and building rubble for use in the Indiana highway system. The information was obtained from a review of published literature and recent unpublished reports and the responses to a questionnaire distributed to many of the state highway agencies regarding the use of concrete recycled from pavements and building rubble.

Based on the results of this work, the following guidelines were developed on the use of concrete recycled pavements and building rubble in the Indiana highway system.

1. When feasible, the use of recycled concrete as aggregates in concrete pavements should be allowed when it fulfills requirements of natural aggregates.

2. In any project involving the use of recycled concrete the cost of reprocessing of aggregate and removal of steel reinforcements should be considered and, in addition, the savings in reduced landfill use should be considered as well. In general, the savings in landfill use should offset the cost of crushing, otherwise the crushing process will not pay for itself and it becomes more economical to use virgin aggregates.

3. A specific volume has not been found to insure that recycling the existing pavement provides economical benefits. Many factors must be taken into consideration when dealing with recycling concrete pavements, and in many cases, the decision may be left to the contractor to decide whether to recycle.

4. In Indiana, most of the counties have at least one aggregate source. These sources might not always be conveniently located near a project and at some point consideration has to be given to how long these sources will be able to supply the aggregate.

5. Due to environmental concerns, in some urban areas, it is less expensive and more environmentally acceptable to re-use the concrete than to dispose of it. Therefore, when a concrete pavement will be removed before a new pavement is placed, the project is a prime candidate for recycling. The old pavement is a source of aggregate in the new concrete, and the need and expense of disposing the material removed can be eliminated. Further, if the project is large enough for an on-site aggregate plant, the materials' transportation costs are reduced. 
6. From the literature reviewed, there was not a fixed dollar amount determined that should determine the choice of recycling when a pavement has to be replaced. The general consensus is that each recycling job should be determined on a project-by-project basis.

7. The use of recycled aggregate for concrete production is expected to increase in the future as both the demand for roadbase material and the price of recycled aggregate is foreseen to decrease.

8. To date, concrete recycling has been involved primarily with the use of crushed pavement concrete as aggregate in new pavements. It has been determined that recycled concrete can best be used as a substitute for coarse aggregate only.

9. Crushed concrete can be used in many applications for the recycled pavement. Examples of the applications are :

- Pavement applications: structural pavement, shoulder, road surfacing, pavement base, sub-base, econocrete

- Non-pavement applications: fill, soil stabilizer

- Flowable fill

10. The use of recycled fine aggregates should be carefully monitored and should not be used for the development of medium to high-strength concrete.

11. Fines should not be used in the sub-base, embankment under abutments, and locations surrounding filters.

12. The quality of the recycled aggregates should be monitored to assure concrete is not developed with more than negligible contaminants. The allowable percentages of contaminants in recycled concrete set by most states is the same as those set for virgin aggregates and must meet standard specifications. Generally, the recycled concrete has shown to be of acceptable quality and can pass state specifications when mixed proportions are processed properly.

13. When pavements on which salt has been used during the winter months for de-icing purposes have been considered for recycling, the contamination of the pavement due to the chloride content has been questioned. Excessive chloride contents require expensive chloride control measures, including the use of epoxy coated steel bars instead of plain steel bars.

14. As long as plasticizing, air-entraining, and retarding admixtures are used in quantities not exceeding manufacturers' recommended dosages, the presence of chemical and mineral admixtures in recycled aggregates has no significant effect on slump, air content, or setting time of fresh recycled aggregate 
concrete, or on compressive strength of hardened recycied aggregate concrete.

15. The risks and liability of recycled concrete do not differ very much from those risks and liabilities associated with concrete made with virgin aggregate.

16. The contaminant that gives the most concern is asbestos which is a toxic waste and should not be combined in other building demolition material. Another contaminant that causes concern when mixed with other demolished material is lead paint which is a hazardous material. Other contaminants include chlorides, sulfates, and glass which can pose potentially serious durability problems.

17. An expert system is being developed by J. Clifton and $\mathrm{L}$. Kaetzel at the National Institute for Standards and Technology in Gaithersburg, Maryland, under SHRP contract C-206. The CONMAT (Concrete Materials) and CONPAV-D (Concrete Pavements Diagnostics) systems may be useful in gaining a better understanding of the consequences and interactions of property changes for concretes in transportation. The CONMAT program covers recycling concrete and gives recommendations on testing and the use of aggregate; selection and testing of fly ash; and recycled mix designs. These programs should be available in spring of 1993. A state agency wishing to evaluate the CONMAT or CONPAV-D system should contact Mr. J. Kaetzel.

Several recommendations are provided below for consideration by INDOT:

- Develop standard specifications, similar to those for virgin aggregate and the concrete Pavement Evaluation System (used by the Minnesota DOT), to assure quality of the recyclea material.

- Use a small section (less than 5 miles) that is in need of major rehabilitation to test the process and at the same project use a test section to compare the recycled concrete results with those of conventional concrete.

- Select a location that is distant from a landfill and a virgin aggregate source. Monitor the amount of excessive fines (below 2 $\mathrm{mm}$ ) that enters the recycled concrete mixture or do not use excessive fines for recycled pavement.

- Monitor the progress of the recycled pavement by taking samples of the pavement throughout the duration of the project in order to make possible adjustments and evaluate the pavement through its lifetime.

- Give special attention to mixture designs when recycled aggregates are to be used in order to minimize cost while meeting the requirements for concrete pavement.

- Use all of the tests mentioned in quality assurance to determine the quality of the material. 
TABLE OR CONTENTS

Page

Table of Contents.......................... i

List of Tables............................. v

List of Figures. .......................... vi

1. INTRODUCTION

1.1 Background......................... 1

1.2 objectives.......................... 1

1.3 Research Approach.................... 2

2. TECHNICAL FEASIBILITY

CONCRETE FROM PAVEMENTS

2.1 Characteristics...................... 3

2.1 .1 volume......................... 4

2.1 .2 Composition.................... 5

2.1 .3 Relative Proportions............... 6

2.2 Required volume..................... 7

2.3 Type of Plants for Recycling............... 7 2.3.1 Mobfle Plants.................... 7

2.3 .2 Fixed Plants.................... 8

2.4 Equipment for separation................ 9

2.4 .1 Demolition..................... 9

2.4 .2 Crushing operation................ 11

2.4 .3 Othex Removal.................... 14

2.5 Size of Concrete After crushing............ 14

2.6 Storage and stockpiling............... 15

2.6 .1 Considerations.................. 15

2.6 .2 Problems...................... 15

2.7. Scheduling for Recycling. ............... 16

2.7 .1 Time Requirement................ 16

2.7 .2 Crew size...................... 17 
3. ECONOMIC FEASIBILITY

3.1 Cost of Disposal. ...................... 19

3.2 Cost of Recycling..................... 20

3.2 .1 Crushing and Handling.............. 20

3.2 .2 start $u p$ cost................... 21

3.2 .3 Sale cost...................... 21

3.3 Savings........................... 22

3.3 .1 Comparison.................... 23

3.3 .2 Locations in Indiana of Aggregate...... 25

3.3 .3 Energy ........................ 26

3.4 Maximum Cost of Recycling................ 27

4. ENGINEERING PROPERTIES

4.1 Types of Tests and Limits................. 29

4.1.1 Properties and Mixture Design of Fresh

Recycled Aggregate Concrete.......... 30

4.1.2 Mechanical Properties of Hardened

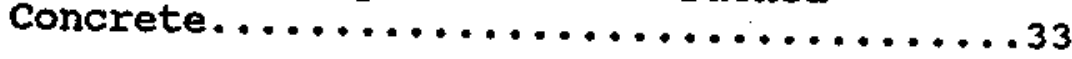

4.1.3 Durability of Hardened Concrete.........41

4.2 Mixture Design........................44

5. END USES

5.1 Applications........................44

5.1 .1 Pavement Applications............. 48

5.1 .2 Non-pavement Applications........... 50

5.1.3 Flowable Fill Application........... 51

5,2 Use for Concrete Fines................. 53

5.2 .1 Fines in soil................... 54

5.2 .2 Fines in Concrete $\mathrm{Mix} . \ldots \ldots \ldots \ldots . \ldots . \ldots 54$

6. QUALITY OF MATERIAL

6.1 Iimits on Contaminants................ 57

6.1 .1 D-cracking...................... 58

6.1 .2 salt.......................... 59

6.1 .3 others........................6 60 
6.2 Strategy for Quality Assurance...........61 6.2 .1 standard Tests.................61

6.3 Concluding Comments.................663

7. RISK ASSESSMENT AND LIABILITY ISSUES

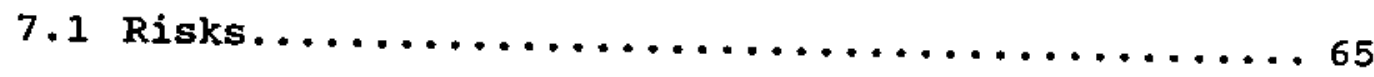

7.1 .1 Economical...................65

7.1 .2 Technical...................66

7.1 .3 Environmental and Health..........67 67

7.1 .4 Political....................68

7.1 .5 Time........................68

7.2 Liability ........................... 69

7.2 .1 Use of Reinforced Concrete..........69 69

7.2 .2 Service Life..................69

8. BUILDINGS

CONCRETE AND OTHER MATERIALS FROM BUILDINGS

8.1 volume............................ 71

8.2 Potential Problem................... 73

8.2 .1 Contaminants..................... 73

8.2 .2 Specifications................. 73

8.2 .3 Toxic Waste................... 75

8.2 .4 Hazardous Waste................ 75

8.3 Applications for Concrete............. 76

8.4 Applications for Non-concrete components...... 76

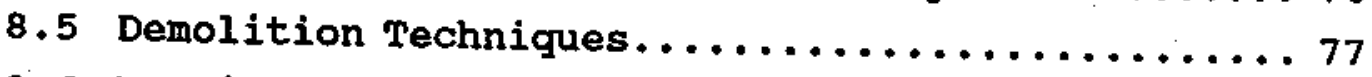

8.6 Roofing Material.................. 80

8.7 Bricks.......................... 81

9. SUMMARY, CONCLUSION AND RECOMMENDATIONS

9.1 summary $\ldots \ldots \ldots \ldots \ldots \ldots \ldots \ldots \ldots \ldots \ldots \ldots \ldots \ldots . \ldots . \ldots \ldots$

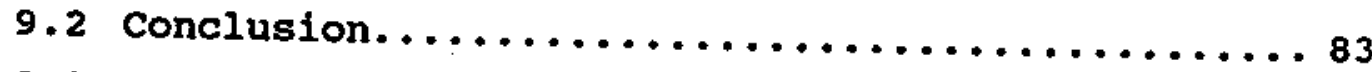

9.3 Recommendations.................... 86 
10. INDIANA SPECIFICATIONS

10.1 Guidelines For Portland Cement Concrete Pavement Recycling Feasibility studies...........89

10.2 Recycling Existing concrete Pavement as coarse Aggregate in New Concrete Pavement........ 91

10.3 Recycling Existing concrete Pavement as coarse Aggregate in Bituminous Concrete and Compacted

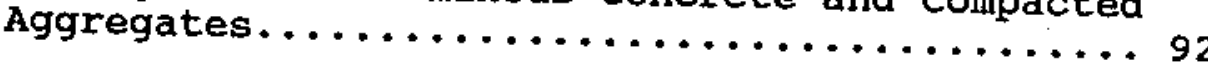

11. REFERENCES

11.1 Literature search..................... 94

11.2 References cited..................... 94

11.3 other References..................... 100

Appendix A: Summary of Questionnaire

A.1 Questionnaire......................... 112

A.2 Responses of Various State Agencies.......... 116 
IIBT OF TABLBB

Table

Page

3.1 Summary of Various Recycling Projects and the Savings

Realized by Using Recycled Concrete............ 23

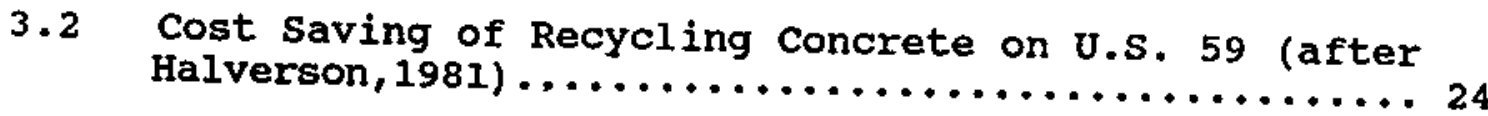

3.3 Comparison of Cost of Aggregates Produced from Reclaimed PCC Pavement to Cost of Virgin Aggregate (after Anon, 1989) ......................... 25

4.1 Effects of Using Fresh Recycled Aggregate Instead of Natural Aggregate........................ 32

4.2 Compressive strength of original and Recycled concretes

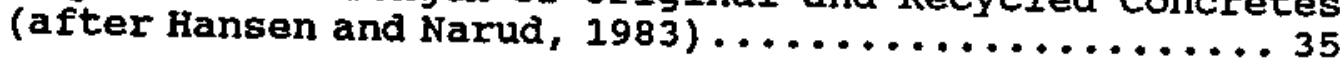

4.3 Effects on Mechanical Properties When Using Recycled Aggregate Instead of Natural Aggregate........... 40

4.4 Effects on Durability When Using Recycled Aggregate Instead of Natural Aggregate.................44

6.1 Results of a Test for the Suitability of old concrete Pavement as a Source for Recycled Concrete Aggregate (after Hoep fner, 1983) ......................63

7.1 Benefication of Aggregates (after Mindess and Young, 1981) ............... 67

8.1 Prediction of Construction, Remodeling, and Demolition Waste Composition in the United states (after Jones, 1973) .......................... 79

9.1 Summary of Incentives for Using Recycled Concrete Pavements............................... 88 


\section{IIBT OP FIGUREB}

Figure

Page

2.1 Flow Chart for Production of Recycled Base course

Material (from Yoshikane, 1988)............... 12

2.2 Pavement crushing Operation (from Van Matre and

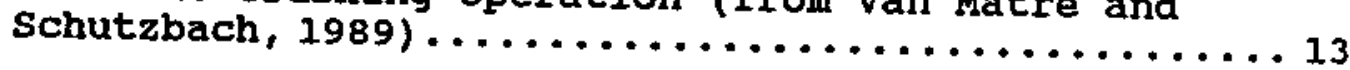

8.1 Prediction of Construction, Remodeling, and Demolition Wastes Generated in the United States

(from Jones, 1973) ........................ 72 
SECTION 1

INTRODUCTION

\subsection{Background}

Reconstruction of the nation's Interstate Highway System has required many state Transportation Agencies to make difficult decisions about pavements. A basic decision is whether pavement replacement would provide lower life-cycle costs than either pavement rehabilitation or resurfacing. The condition of the existing pavement and a consideration of both past and future traffic loadings influence their choices.

Pavement replacement requires that the existing pavement be removed and the removed material must either be recycled or disposed of in a suitable fashion. In many instances the most ecoriomical and/or suitable fashion will be to recycle the concrete by utilizing it in components of the new pavement. other building debris may have similar potential.

\section{2 objectives}

The objective of this proposed research investigation was to assess the suitability of using concrete aggregates that are recycled from (1) concrete pavements, and (2) building rubble, for use as a highway construction material (i.e. in structural pavements, shoulders, base, subbase and subgrade in pavements) in the state of Indiana. 


\subsection{Researoh Approach}

The tasks necessary to accomplish the objectives included:

- review available information on concrete recycling use in highway construction and additional uses for materials from building demolition;

- synthesis of the information that answers the study objectives;

- reporting recommendations to the INDOT.

In order to evaluate the recycling alternative for the state of Indiana, it was desirable to investigate and discuss the findings of other states. states with similar topography and climate, and with recycling experience, were chosen. Michigan, Iowa, and Illinois, all have experience with recycling concrete hence, were used often to determine how recycling concrete would benefit Indiana. 
SECTION 2

TECHNICAL FEASIBIIITY

\section{INTRODUCTION}

This section describes the various aspects of technical feasibility with regards to recycling. To begin, the characteristics of recycled concrete are outlined, including the volume, composition and relative proportions as compared to conventional concrete. Required volume is then discussed. This section also presents the types of recycling plants, mobile and fixed, and the equipment needed for separation in both demolition and crushing operations and the size the concrete should be after crushing. This section presents storage and stockpiling considerations and problems. Lastly, the scheduling for recycling projects is discussed, including time required and the size of crew needed.

\subsection{General Characteristics of Recycled Concrete}

The condition of the concrete to be recycled is a major factor in the decision of whether to recycle. Recycling may degrade very high quality aggregates slightly, but Michigan Department of Transportation (MDOT), as well as other states' DOT', have found that recycling generally produces good quality aggregate at high production rates.

Most demolished concrete can be processed to yield aggregates for production of new concrete. However, recycled aggregates are different from conventional concretes because 


\subsubsection{Relative Proportions}

The recycling of existing pavement will produce about 50 percent more recycled aggregate than is needed, to replace the same section with a pavement of equal thickness. However, it may not be advisable to use fine recycled aggregate less than standard sieve No.8 for production of new concrete (Hansen, 1986). The use of fines in concrete will be covered in Section 5.2.2. Results have shown that during crushing approximately 70 percent coarse aggregate recovery can be expected, and approximately 20 percent will be lost to fines. The remaining 10 percent is lost during the removal and handling operations (Highway and Heavy construction, Feb. 1988).

old pavement will provide more than enough coarse aggregate for repaving. crushing a 9-inch pavement provides enough coarse aggregate to pave a new 10-inch pavement with concrete shoulders on both sides (Arnold, 1988). When the six lanes on 8.7 miles of the John c. Lodge Freeway in Detroit was restored, recycling provided enough coarse aggregate for the new pavement and half of the subbase coarse. When reconstruction needs to be done, it is evident that recycling can produce enough aggregate without having to haul in virgin material from elsewhere. It can therefore alleviate the aggregate producers' depletion of reserves and reduce energy costs associated with hauling and the subsequent air pollution. 


\subsection{Required Volume}

A specific volume has not been found to insure that recycling the existing pavement provide economical benefits. Many factors must be taken into consideration when dealing with recycling concrete pavements, and in many cases the decision may be left to the contractor to decide whether to recycle. Projects as small as 3 miles of improved road have demonstrated the successful use of recycled concrete aggregate to produce a smooth and durable pavement. The total cost per square yard to recycle and place pavement in this small project was slightly more than if using virgin aggregate. Savings were realized in this project by not having to haul the existing pavement to a landfill and haul in virgin aggregate (Hoepfner,1984).

\subsection{Types of Plants for Recycling}

\subsubsection{Nobile plants}

The main reason that mobile plants have been used on certain projects is the efficiency of having the plant on the site. There are several benefits to mobile plants:

- reduced transportation costs

- localized particulate emissions and noise

- simplicity in relocation for a large job

- time savings from not having to haul material far away for recycling 
Most mobile plants produce about 300 tons of crushed material per hour and some contractors find it easier to run the plant 18 hours a day since it is located on the job. According to Ray Gordon (1978), the plant can be set up in 4 to 6 hours and dismantled in about the same amount of time. Improvements in technology have produced a portable one-piece crushing plant that can travel to any job site, eliminating the need for a crane for setup.

In Chicago, one material company runs a regular concrete recycling operation. wrecking contractors dump old concrete for a fee per trailer load and then a portable crusher moves from site to site using the large stockpiles that have accumulated from various projects.

\subsubsection{Fixed plants}

Producers may consider investing in reclaimed-recycling systems for several reasons:

- steady increase in dumping fees

- shortage of landfills

- large anount of concrete being demolished

- shortage of aggregate available in some areas

Contractors may purchase crushers and accept material from various jobs to recycle. These contractors are successfully able to produce enough recycled aggregate to make the system profitable. New crushing machines combine the crusher and feeder into a complete crushing plant at ground level. The continuous crushers are offered today in the 
capacity range of 100 tons per hour to 2,000 tons per hour with piece sizes up to $1.5 \mathrm{~m}$ being processed without any difficulty (Snell, 1988).

Fixed plants have the advantage of being able to recycle concretes from roads and buildings. These plants are generally larger and able to produce more recycled aggregate per hour, as compared to the mobile plants.

\subsection{Equipment for separation}

Since the nation's first PCC highway recycling job in 1976, on a 1.4 mile project in Lyon County, Iowa, it has been obvious that the greatest need has been for a better method of concrete breaking so that (a) the slab would not be punched into the subgrade, and (b) a well broken, uniformly-sized product could be made at a satisfactory rate.

Pavement removal for recycled concrete can be accomplished by using conventional removal methods. Additional care must be exercised in cleaning the shoulder material away from the pavement slab and in removing the broken pavement to prevent excessive contamination by the base material (Lane, 1982).

\subsubsection{Demolition}

One of the most successful break-out tools is the resonant pavement breaker developed in the United states. This self-propelled machine employs a $12 \mathrm{ft}$. beam that vibrates about 1.5-in., 44 times a second. The 50 ton machine 
normally advances at 150 to $200 \mathrm{fpm}$ wile crushing the slab and almost completely separating rubble from steel rebars (Highway and Heavy Construction, 1987). one of the most attractive features of the resonant breaker is that it does not transmit any vibrations, therefore there would be no damage to underground utilities or adjacent slabs. For large jobs, it has been reported to work 5 times faster and at least 20 percent cheaper than conventional equipment (Roth, 1984). For smaller jobs, such as a one mile project, contractors have chosen conventional equipment, such as the Thumper, for economic reasons. The Thumper, a double acting pile hammer mounted on a trailer, covers about 150 to $200 \mathrm{sq}$. yd. per hour (Highway and Heavy Construction, Feb. 1984). When there is an inordinate amount of large pieces of broken concrete from the grade, a wrecking ball is used to break these into a size that the crusher can accommodate. For a list of different pavement breakers see Roth (1984).

After the pavement is broken, a "rhino-horn" excavator is used to separate most of the steel for projects with concrete reinforcement. Track-type excavators are preferred to wheeler loaders because of the eliminated problem of wire mesh puncturing tires. Workers can follow this operation with hydraulic shears, cutting and pulling out loose reinforcing steel and putting it off to the side for pick-up and salvage. Approximately 90 to 95 percent of the reinforcing steel can be removed this way (Hansen, 1986). Another simple conventional method for separating wire mesh is by repeatedly shaking and 
dropping loads to the ground before finally loading the hauler. Any remaining steel reinforcement is removed at the crushing plant. After this, the broken pavement is loaded onto trucks and taken to be stockpiled at a crushing facility. Newer portable crushing plants can accept concrete containing embedded rebar steel at 15 percent of the total weight (Rukavina and Mitchell, 1989).

\section{4 .2 crushing operation}

Many types of jaw crushers, most with similar characteristics and benefits are available. Jaw crushers can reduce an average of 400 tons per hour of concrete rubble to 5-in. minus size before crusher fines are screened out and residual steel removed by electromagnets (Highway and Heavy Construction. Feb. 1985) . The presence of steel reinforcement in concrete does slow operations. Previously, breakdown of the crushers or constant replacements of worn parts due to the steel were problems, but now more advanced crushers can continue normal operations even with the presence of steel. More wire is shaken out during. plant loading, and two magnets retrieve the rest, with little hand picking required (Highway and Heayy Construction, April 1984). Shakers in the crushing operation are used to sort the crushed concrete into different sizes of coarse aggregate. Figure 2.1 shows a flow chart of the production process. 


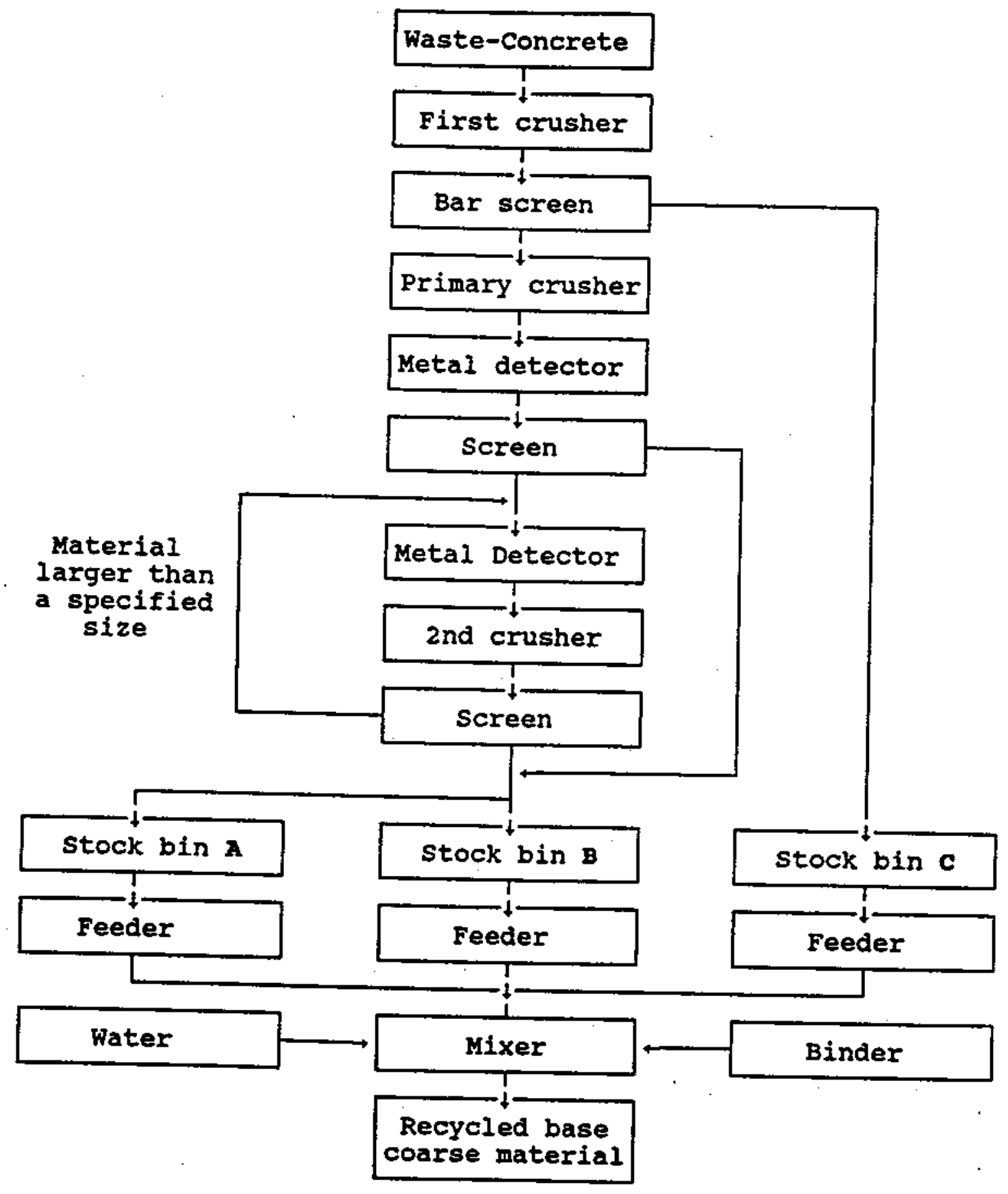

7igure 2.1: Flow chart for production of recycled base coarse material (from Yoshikane, 1988) 


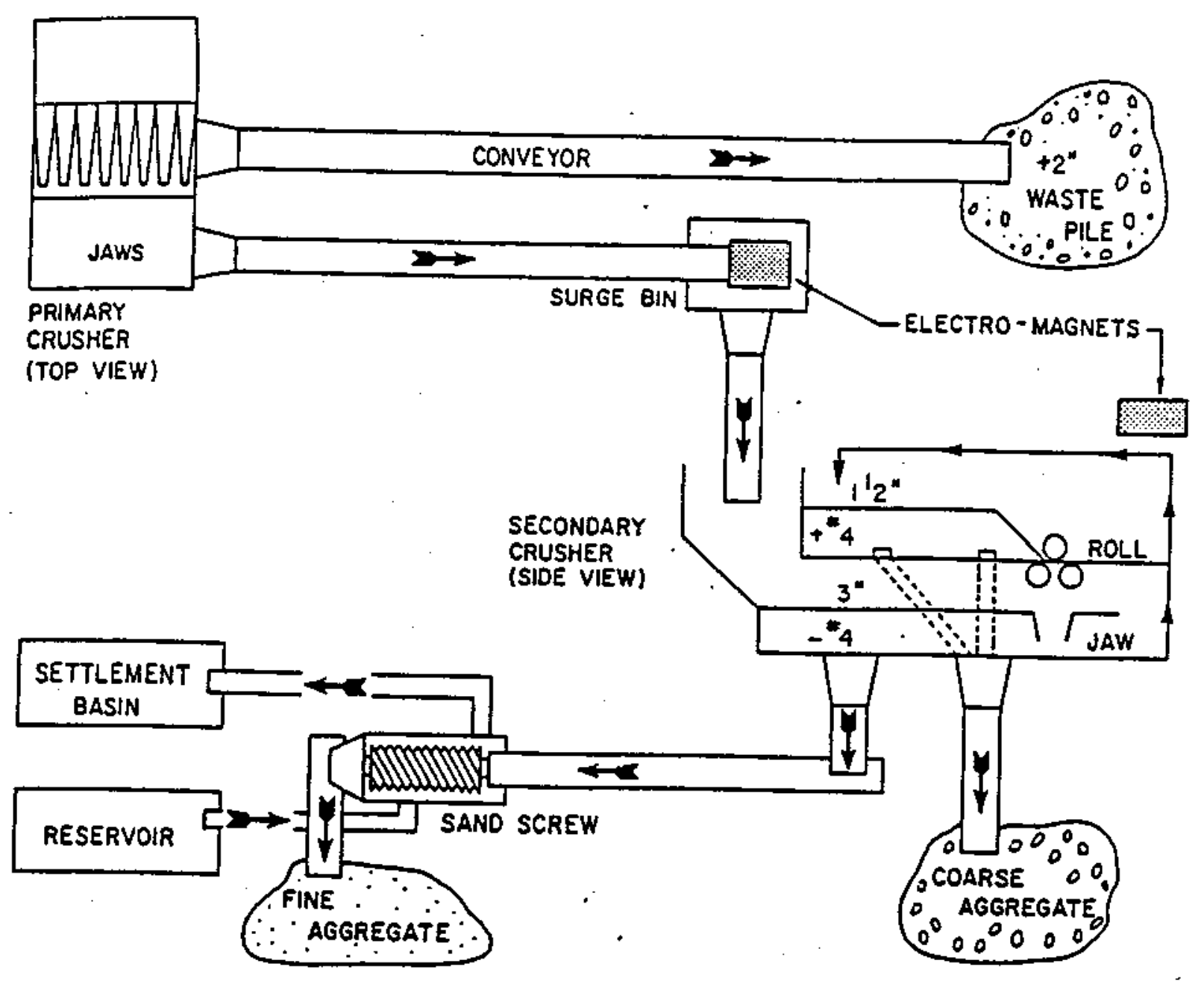

Pigure 2.2: Pavement Crushing Operation (from Van Matre and Schutzbach, 1989) 


\subsubsection{Other Removal}

After primary crushing, dirt and other fine impurities are eliminated by passing the crushed material over a set of scalping screens and wasting of all material below a specified size. Other techniques, such as the wet classification techniques, by which water jets are used in combination with a float-sink technique, are also used to remove lightweight contaminants from heavier bulk material. Inclined vibrating screens were found to be most efficient in separating coarse material.

Weather is another consideration in the removal process. Contractors have limited the removal operations to ary weather conditions, so as to lessen the amount of subgrade that adheres to the old pavement (Bergren, 1977).

\section{5 size of concrete After crushing}

General specifications call for pavement material to be crushed to pass through a 1.5-inch sieve. Processing equipment should include a screen so that excessively fine material passing through the No. 8 sieve can be removed (Bergren, 1977). Past experience suggests that when crushing the old pavement splitting should be required for the crushed products at about the $3 / 8$ inch screen size to facilitate the control of mix proportions. Further statistics on the percentages passing and sieve sizes can be found in articles by Hansen, 1985; F.R. Van Matre, 1989; and W.A. Yrjanson, 1981. 


\section{6 storage and stockpiling}

\subsubsection{Considerations}

As mentioned above, separating the crushed products has been shown to be very important. The separation is between material larger and smaller than the 3/8-inch screen size. The crushing operation separates these materials, with approximately 60 percent to 65 percent coarse fraction retained on the $3 / 8-$ inch and 35 percent to 40 percent minus 3/8-inch material (Halverson, 1982). Stockpiles should be made for each material size so that mixture designs can be assured that the proper recycled aggregates are not being mixed with aggregates of other size fractions. The stockpiles should be covered as suggested by standard specifications, as to limit the influence of the weather on the water content and to avoid dust and other small particles mixing with larger size material (Lane, 1982).

\subsubsection{Problems}

When considering the storage and stockpiling of concrete, problems can arise when recycled aggregates from aifferent sites are stored together. Difficulties have been found when medium-strength and high-strength concrete are produced from recycled aggregates of non-uniform quality. The large variations of compressive strength test results, which can be expected for such concretes, will make it difficult and uneconomical to meet statistical compliance criteria in modern 
concrete codes when the mixed designs are being produced. For this reason, it has been suggested that the aggregate be separated according to the quality of the material before and after it has been crushed. This way, more control can be maintained when producing the concrete to assure that the specifications required are followed.

\section{7 scheduling for Recycling Projects}

On recycling projects, it is necessary to have complete coordination between the processing of the coarse aggregate and the production of the concrete paver. The aggregate processing plant is the key item in a recycling project. For example, during the recycling project on I-94 in Michigan the aggregate plant was run one shift for the first half of the job and two shifts for the second half of the job to coordinate with the production of the paver (McCarthy, 1985). This is another reason it is beneficial to have a mobile plant at the project, so that control and coordination can be simplified.

As with any highway rehabilitation project, the scheduling for a recycling project should be done at a time when the amount of traffic is as minimal as possible.

\subsubsection{Time Requirement}

The amount of time that is required to do the actual breakout and recycling varies from project to project, depending on the number of shifts or hours worked per week. 
On the I-94 project in Wisconsin, it was possible to crush and screen two miles of 9-inch, 24 foot wide pavement per week on two shifts. In order to minimize the amount of travel time required on large projects with mobile plants, the plant is usually moved several times during the project (Highway and Heavy Construction, May 1985).

\subsubsection{Crew bize}

Most crews work 10 to 12 hour days during the construction period. There is usually a crew of 5 at the crushing plant, working 10 hour days (Highway and Heavy Construction, May 1985). Crews range from 30 to 100 workers, depending on the size and stage of the project. Some projects, due to traffic considerations, have crew working 4 days at 12 hours and then a $1 / 2$ day on Friday (Highway and Heavy Construction, Sept. 1984). 


\section{SECTION 3}

\section{ECONOMIC FEABIBILITY}

\section{INTRODUCTION}

This section outlines the various components of the economic feasibility of recycling concrete pavements. Included in this are the cost of disposal, cost of recycling, savings, and maximum cost of recycling. Further details will be provided for the cost of recycling to explain the crushing and handling, start up, and sale costs. The savings will compare the cost of the recycling option, as opposed to conventional practice, show where aggregate sources are located in Indiana, and discuss the energy benefits of recycling concrete pavements.

\section{NOTE ABOUT COSTS:}

The following sub-sections include many prices to demonstrate the economic feasibility for recycling. In order to provide comparable costs, the dollar amounts for the various recycling activities were converted to 1990 dollars by use of the Price Trends for Federal-Aid Highway Construction, published by the Federal Highway Administration; Publication Number FHWA-PD-91-009. The price was converted from the given year to 1987 (the base year) and then to the annual price for 1990. An attempt to convert the dollar equivalent between. states was not made because of the inaccuracy that would likely happen. Many of the projects occur away from large 
cities, from which data can be converted, so the interpolation would not be accurate.

\subsection{Cost of Disposal}

The cost of hauling material to a landfill can be excessive if the landfill's location is remote. When recycling is not used, there is generally twice the transportation cost, because it is not only necessary to transport the new aggregate to the site, but also to haul the old aggregate to a landfill. A major transportation cost arises when it is necessary to transport rubble to a landfill that is greater than 50 miles away, which has been found not to be uncommon in nearby chicago.

Dumping fees add to the mileage and time costs, when considering the cost of disposal. The dumping fee ranges from about $\$ 3.00$ per cu. ya. in Michigan's urban areas to $\$ 20$ per cu. Yd. In washington D.C., and $\$ 7.50$ per cu. yd. in Chicago (Highway \& Heavy Construction, Feb. 1982).

When the Edens Expressway, in Chicago, was rehabilitated using recycling, it eliminated the cost of disposal of 350,000 tons of pavement rubble and provided material for the porous granular backfill and a granular base material.

In some Michigan cities commercial crushing sources accept the rubble without charge. This appears to be a good way to initiate a commercial crushing business, since smaller contractors lacking the recycling equipment can buy from these 
sources, thus the saving of valuable resources is encouraged, as well a reduction in the amount of material landfilled.

\subsection{Cost of Recycling}

The Michigan DOT estimates that recycled aggregate costs about the same as virgin aggregate for concrete pavements. This includes the cost of disposing of old pavement if new aggregate is used (ENR, Feb. 1988). Michigan would appear to be a reliable source to obtain expected costs for Indiana, due to its similar characteristics in weather, topography, and close proximity.

According to an article in Highway \& Heavy construction (February 1982), the total cost of recycling concrete coarse aggregate, in Michigan, has been from $\$ 4.25$ to $\$ 4.55$ per ton. In Iowa and Minnesota such costs have been lower, because of the greater experience of the contractors, larger quantities of recycled material being used, and a wider variety of uses for recycled material. For these reasons, Indiana can expect the cost of recycling concrete to be higher than other states until the Indiana contractors become familiar with the process.

\subsubsection{Crushing and Handing}

The crushing and handling operation consists of removing and salvaging the existing concrete pavement in a manner which disrupts the underlying existing subbase as little as possible, transporting the salvaged materlal to a stockpile 
site, and crushing the material to meet gradation specifications for concrete aggregate. The specifications usually follow the guidelines set by the state.

In the survey sent to the various states DOT's, Iowa reported crushing to cost $\$ 8.00$ per ton while Nebraska quoted $\$ 10.40$ per ton. The cost for removal of nearly $156,000 \mathrm{sq}$. yds. of pavement was given as $\$ 6.05$ per sq. yd. for a job in Iowa (Chase, 1985). The removal and crushing of 1.5 miles of pavement on U.S. 75, during 1979 in Iowa, cost nearly $\$ 10.60$ per sq. yd. (Bergren, 1977).

\section{2 .2 start up cost}

Production equipment is now available to allow the effective use of recycling, and cost benefits of ten percent or more are being reported (Anon, Jan. 1989). The cost of setting up a portable crusher will total $\$ 7500$ (Highway \& Heavy construction, Feb. 1982). This is minimal compared with off-site handling.

Frondistou-Yannas estimated in 1977 , that the initial set up cost is assumed to be $15 \%$ of the purchasing cost for the equipment. In 1984, McCarthy and Maccreery estimated the cost for crushing plant, for a recycling job in Michigan, to be approximately $\$ 1.5$ million (1985).

\subsubsection{Bale cost}

The price for recycled aggregate was calculated to be $\$ 3.92$ per ton according to Frondistou-Yannas and Itoh (1977). 
A Houston contractor who crushed and sells concrete rubble for roadway base, sells recycled concrete material at his plant for about $\$ 2.20$ a ton less than the cost of virgin material (Munn, 1988).

Besides the sale of recycled aggregate, other material from recycling pavements can be sold. For example, a Michigan contractor sells salvage steel at about $\$ 40$ per ton to help offset his costs for purchasing and maintaining the recycling equipment (Highway \& Heavy Construction, Feb. 1982).

\section{3 savings}

Recycling has begun to demonstrate cost savings over the use of new materials for major maintenance and rehabilitation of pavements. The Federal Highway Administration estimates the pavement industry generated $\$ 105.5$ million in savings using recycled materials in 1985 (Anon, Jan. 1989).

The savings for recycling pavements are realized after contractors have experience with recycling. Many states did not find notable savings during their "test project", but after working with the recycling of concrete, they found potential for savings. Most of the projects where the greatest amount of savings were encountered were sites far from virgin aggregate sources and landfills. 
Table 3.1 is a summary of various recycling projects and the savings realized by using recycled concrete:

Table 3.1 Recycling Savings by state

\begin{tabular}{|l|l|}
\hline STATE & SAVINGs (in dollars) \\
\hline North Dakota & $35-50,000$ per mile of 4-lane \\
\hline Minnesota (US-59) & over 44,000 per mile of 2-lane \\
\hline Michigan & $50-60 \%$ of the cost for buying \\
\hline Oklahoma & new aggregate \\
\hline Iowa (I-680) & 90,000 per mile of 4-Iane \\
\hline Iowa (Rt-20) & nearly 7,000 per mile \\
\hline
\end{tabular}

\subsubsection{Comparison}

A comparison of costs for recycling portland cement concrete as opposed to conventional concrete paving was assembled by personnel in the Mn/DOT Estimating Unit for the project on U. S. 59, a 16-mile segment which had "D"-cracked concrete pavement. Table 3.2 is taken from the study on the project (Halverson, 1982). An additional table (Table 3.3) is included for the comparison of savings using the recycling option as opposed to the conventional method. 
Table 3.2

Cost saving of recycling concrete on U. S. 59 (from Halverson, 1982)

\begin{tabular}{|c|c|c|c|}
\hline TEM & QUANTITY & RECYCLE COST & CONVENTIONAL COST \\
\hline Remove Concrete Pavement & 229,170 sq. yds. & & $\$ 401,047$ \\
\hline $\begin{array}{c}\text { Salvage Concrete Pavement, } \\
\text { Crush and Stockpile }\end{array}$ & 229,170 sq. yds. & $\$ 595,842$ & 80,101 \\
\hline Stabilizing Aggregate & 24,238 Tons & & $\$ 60,595^{\star} \star$ \\
\hline Class 3 Shouldering* & 23,114 Tons & & $\$ 57,785^{\star \star}$ \\
\hline Class 5 Shoulderlng* & 21,238 Tons & & $\$ 53,095^{\star \star}$ \\
\hline Recycled Structural Concrete & 52,165 sq. yds. & $\$ 1,289,950$ & ? \\
\hline $\begin{array}{c}\text { Recycled Structural Concrete } \\
\text { (high-earty strength) }\end{array}$ & $963 \mathrm{cu}$. yds. & $\$ 28,890$ & \\
\hline Standard Structural Concrete & $1,308 / 53,959$ cu. yds. & $\$ 51,954$ & $\$ 2,077,422$ \\
\hline $\begin{array}{c}\text { Standard Structural Concrete } \\
\text { (high-early strength) }\end{array}$ & $31 / 994 \mathrm{cu}$. yds. & $\$ 1,395$ & $\frac{\$ 43,736}{\$ 4}$ \\
\hline TOTAL & & $\$ 1,968,031$ & $\$ 2,693,680$ \\
\hline
\end{tabular}

- Portion of Class for which recycled material was available

* Differential cost between recycled material and natural aggregate from a gravel pit . 
Table 3.3 is a comparison of the cost of aggregates produced from reclaimed PCC pavement to the cost of virgin aggregate (after Anon, 1989)

Table 3.3 :

\begin{tabular}{|l|c|c|c|c|c|c|c|}
\hline State & Project & Year & Miles & Coarse & & Fine & PCC \\
\hline N. Dakota & I-94 & 1983 & 12 & $\$ 14.00$ & & 11.00 & $\$ 3.32$ \\
\hline N. Dakota & I-29 & 1983 & 11 & 12.00 & & 6.75 & 8.65 \\
\hline N. Dakota & I-94 & 1984 & 13 & 13.00 & & 11.00 & 6.33 \\
\hline Wisconsin & & & & & 4.50 & & 6.75 \\
\hline Wisconsin & & & & & 5.50 & & \\
\hline
\end{tabular}

\subsubsection{Locations in Indiana of Aggregate}

A map from the Division of Materials and Testing, of the INDOT, can be made available, showing approved aggregate sources inside and bordering Indiana. Because many of the savings from the previous examples were from projects generally located away from major aggregate sites, it is necessary to determine the closest aggregate site for a project location, when considering recycling of pavements in Indiana. knowing the location of the nearest aggregate source, a cost evaluation can be made to determine the possible benefits of recycling. 


\subsubsection{Energy}

Energy expenditure can vary considerably depending on the location of the crushing plant, concrete plant, waste sites, haul distances, etc. and must be considered on a project-toproject basis.

The Connecticut DOT completed a detailed study of the energy requirements for recycling aggregate concrete for a one mile project on Interstate Route 84 in the Town of Waterbury. This study can be found in construction of a Recycled portland Cement Pavement, September 1980 (Lane, connDoT).

The result of the energy considerations are:

- Total energy required for $1 \mathrm{cu}$. yd. in place using the conventional method $=2,119,846$ $\mathrm{BTU} / \mathrm{cu}$. yd.

- Total energy required using the recycled method was $2,168,357 \mathrm{BTU} / \mathrm{cu}$. yd.

For the same project the savings of natural resources due to recycling of portland cement concrete for each cubic yard of material used are:

Quantity

Coarse Aggregate

Fine Aggregate

Energy savings
$2064 \mathrm{lbs} / \mathrm{cu} . \mathrm{yd}$.

$278 \mathrm{lbs} / \mathrm{cu} \cdot \mathrm{yd}$.

18,962 BTU
Percent Savings $100 \%$ $26 \%$

$1 \%$ 
Halverson (1982) reported on the 16-mile recycling project in Minnesota that the material production for recycled concrete would require more energy than materials production for conventional concrete. However, the energy requirement for transportation of construction materials was less for the recycling option than for the conventional paving. This amounted to a savings of 65,300 gallons of gasoline.

\subsection{Maximum cost of Recycling}

One of the main criteria that has been given for determining the maximum cost of recycling is that the cost of the recycled aggregate should be about half of the cost of virgin aggregate or less (Roth, 1984). Frondistou-Yannas (1977) arrived at the same conclusion and found that recycled aggregate will be in great demand

- in areas where natural aggregate is locaily unavailable

- in areas where natural aggregate, even though available, is in insufficient quantity to meet the demand

- in areas where the quantities of concrete debris generated annually are large enough to permit economies of scale and therefore prices of less than $\$ 3.30$ per ton for the aggregate can be realized (Roth, 1984).

It has been found that, on average, that 0.27 tons of concrete rubble per capita are generated each year in the U.S. 
To realize economics of scale a plant should process at least 110-275 tons of debris per hour. In addition, to produce a reasonable return on investment, the plant should process and sell no less than 200,000 tons of recycled aggregate per year (Hansen, 1986). Stone produces Mike Larson, while speaking at the National Stone Association's 1989 convention, determined that most recycling jobs amount to about 10,000 to 15,000 tons, and that a good year would produce about 120,000 to 150,000 tons of recycled material. Most contracts for big jobs range from 60,000 to 70,000 tons (Rukavina, 1989).

The value of recycled aggregates vary greatly throughout the country. Local savings in water costs through recycling also vary substantially, as do labor costs involved in the operation. Thus it is necessary for each producer to determine how a recycling plan fits into his balance sheet. Many are finding that the high-first-cost equipment pays for itself in a reasonable period (concrete construction, Apr. 1986). It is difficult to put a dollar figure ont he maximum cost of recycling because the final selection ultimately might be decided by non-cost factors, such as the experience of local contractors, time schedules, and shortage of landfills, and conservation of resources. From the literature reviewed, there was not a fixed dollar amount determined that should determine the choice of recycling when a pavement has to be replaced. From the surveys received from the various DOT's, the general consensus was that each recycling job should be determined on a project-by-project basis. 


\section{SECTION 4}

\section{AMGIMGERIMC PROPERTIES}

\section{INTRODDCTION}

This section discusses various types of engineering properties involved with recycled concrete. First, the types of tests and limits used are outlined, including properties and mixture design of fresh recycled aggregate, mechanical properties and durability of hardened concrete. Next, the relationship of old concrete to recycled aggregate is described with regards to cracking and surface distress, and friction testing. Finally, the mixture design is discussed.

Note: The performance, with regard to engineering properties, of using any recycled material wili have the same performance as any conventional aggregate being used. That is, conventional concrete aggregate will vary in their properties and effects the same way recycled aggregate will

\subsection{Types of Tests and Iimits}

Kany agencies are beginning to accept recycled aggregate concrete pavement as a routine aggregate, rather than requiring special testing of it as aggregate. some state highway agencies have developed their own specifications for recycled aggregate concrete in pavements. Indiana specifications can be found in section 10.

A table at the end of each sub-section summarizes the basic impact each property has on recycled aggregate concrete. 


\subsubsection{Properties and uixture Design of Fresh Recycled Aggregate concrete:}

Free-water requirement: According to the wisconsin DOT survey, there is no major change in water demand for concrete made with recycled concrete aggregates, but absorption and stockpile moisture contents are higher than for virgin aggregate.

According to Hansen and Narud (1983), recycled concretes have an approximately 5 percent higher free water requirement, compared to otherwise identical fresh concretes made with natural gravel.

Workability: The Iowa DOT suggests that 30 percent of the total aggregate be natural sand in order to improve the workability, which agrees with a study done by Forster (1985). The wisconsin DOT mentioned that the workability is better with proper proportioning of sand. Illinois added small amounts of natural sand and fly ash to improve the workability for the concrete mix on a 4.14 mile section of I-57 (Van Matre and Schutzbach, 1989). Minnesota requires the use of fly ash at 15 percent replacement in the concrete mix (MinnDoT questionnaire).

Nixon (1978) found it possible to achieve equivalent workability at a lower water/cement ratio by using water reducing admixture. He observed that mixes containing crushed concrete as both coarse and fine aggregate had a lower slump and higher cement content than the control mixes. More information can be found in articles by Ravindrarajah, 1985 and Rasheeduzzafar, 1984. 
Density and aix content: The non-entrained air content of recycled aggregate concrete may be slightly higher than that of control concretes made with conventional aggregate. The density of recycled aggregate concretes is lower than a control mix of virgin materials. Reduction in density may vary from less than 5 percent to more than 15 percent. It is possible to produce recycled aggregate concrete in the laboratory with no significant increase in air content and less than 5 percent lower density, compared with control mixes.

Cement content: For the 1.4 mile project in Lyon county, Iowa, the cement content was approximately 12 percent by volume. According to Hansen (1986), at least 15 percent more cement would be required if new concrete is produced with both coarse and fine recycled aggregate. However, in reality much more than 15 percent extra cement may be required to maintain the same compressive strength as conventional concrete, when both coarse and fine recycled aggregates are used. This is because fine recycled aggregate in itself is known to lower concrete strength by up to 50 percent (Hansen, 1986).

Hansen (1986) concluded that recyclied aggregate concrete made with recycled aggregates always reguires more cement than conventional concrete to obtain equivalent slump and strength. Also, it is uneconomical 
in terms of cement consumption to use fine recycled aggregate in concrete production.

Free water-cement ratio: The basic water-cement ratio rule, which is fundamental to all concrete mix design, applies without modification to all types of recycled concretes. Only the level of strength may in some cases be lowered for recycled aggregate concrete than for conventional concrete (Hansen, 1986).

See Table 4.1 for a comparison of the properties and effects discussed above.

Table 4.1 Effects of Using Fresh Recycled Aggregate Instead of Natural Aggregate

\begin{tabular}{|l|l|}
\hline PROPERTY & EFFECT \\
\hline Water requirement & Increased \\
\hline Workability & Decreased (1) \\
\hline Density & Lower \\
\hline Air content & Slightly increased \\
\hline Cement content & Increased \\
\hline Free water-cement ratio & Preferably lower \\
\hline
\end{tabular}

(1) It is possible to increase this under certain conditions 


\subsection{2 uechanical properties of Recycled aggregate concrete}

Additional information and detailed tests concerning the mechanical properties of recycled aggregate concrete are reported by Rasheeduzzafar and Khan (1984), and Ong and Ravindrarajah (1987).

Compressive strength: Hansen and Narud (1983) found, when other factors are essentially identical, that the compressive strength of recycled concrete is largely controlled by the water-cement ratio of the original concrete. If the water-cement ratio of the original concrete is the same as or lower than that of the recycled concrete, then the new strengths will be as high as or higher than the original strengths.

Hansen and Narud (1983) also found it possible to make recycled aggregate concrete with a water-cement ratio of 0.40 having a $4930 \mathrm{psi}$ compressive strength both after 14 days of standard curing and after 38 days of accelerated curing. This concrete used recycled aggregate from an original concrete with a water-cement ratio of 1.20 , having a compressive strength of 2030 psi at crushing. This confirmed earlier results by Buck (1977) which showed that it is possible to make recycled concretes which are stronger than corresponding original concretes from which the recycled aggregates are derived.

Rasheeduzzafar (1984) attempted to produce highstrength concrete (5800 psi or higher) from medium- 
strength (3335 psi) coarse recycled aggregate. He found the strength of recycled aggregate concretes to be lower than that of corresponding control concretes made with the same water-cement ratio. But with natural aggregate the strength of such control concretes exceeded the strength of the original concrete (3335 psi).

The highest compressive strength obtained for a recycled aggregate concrete was 8875 psi, which had a water-cement ratio of 0.40 , was made using high-strength original and coarse recycled aggregate, reported by Hansen and Narud (1983).

When recycled aggregate concrete is made with coarse and fine recycled concrete, the strength has been found to be 10-20 percent lower than the strength of a corresponding recycled concrete made with coarse recycled aggregate and 100 percent natural sand (Hansen, 1986). The Michigan DOT has limited the allowable amount of recycled fines to 25 or 30 percent of total sand on interstate highway rehabilitation projects and plan to completely prohibit the use of recycled fines on some future work. 
Table 4.2 shows the "compressive strength of original and recycled aggregate concretes after 38 days of accelerated curing. Symbol $\mathrm{H} / \mathrm{M}$ indicates a high strength recycled concrete with coarse aggregate produced from medium-strength concrete, etc." (from Hansen and Narud, 1983).

Table 4.2 Compressive Strength of Original and Recycled Aggregate Concretes, in psi

\begin{tabular}{|l|l|l|l|l|l|l|l|l|}
\hline $\mathrm{H} / \mathrm{H}$ & $\mathrm{H} / \mathrm{M}$ & $\mathrm{H} / \mathrm{L}$ & $\mathrm{M} / \mathrm{H}$ & $\mathrm{M} / \mathrm{M}$ & $\mathrm{M} / \mathrm{L}$ & $\mathrm{L} / \mathrm{H}$ & $\mathrm{L} / \mathrm{M}$ & $\mathrm{L} / \mathrm{L}$ \\
\hline 8874 & 7149 & 5017 & 5090 & 4785 & 3900 & 2146 & 2103 & 1943 \\
\hline 8802 & & & & & & & & 1972 \\
\hline 8787 & & & & & & & & 1856 \\
\hline
\end{tabular}

Modulus of elasticity: Due to the large amount of old mortar with a comparatively low modulus of elasticity which is attached to original aggregate particles in recycled aggregates, the modulus of elasticity of recycled aggregate concretes is always lower than that of corresponding control concretes made with conventional aggregate.

Frondistou-Yannas (1977) found up to 33 percent lower modulus of elasticity for recycled aggregate concretes made with coarse recycled aggregate and natural sand, compared to the modulus of elasticity of corresponding control concretes made with conventional aggregate. 
Gerardu and Hendriks (1985) report a maximum of 15 percent lower modulus of elasticity of recycled aggregate concretes made with coarse recycled aggregate and natural sand compared with corresponding conventional concretes. When the sand was also replaced with crushed concrete fines, a maximum of 40 percent reduction in modulus of elasticity was observed.

Damping capacity: The damping capacity is an intrinsic property which causes vibrations in a specimen to decrease in amplitude even when the specimen is isolated from all sources of energy loss. The most common way of expressing the damping capacity is in terms of logarithmic decrement, which corresponds to the measure of the decrease in amplitude of free vibration (Ravinararajah, 1985).

Ravindrarajah and Tam (1987) found the damping capacity expressed in terms of the logarithmic decrement to be between 16-23 percent higher for recycled aggregate concrete than for conventional control concretes. The damping capacity for both types of concrete increased with the decrease in compressive strength.

Creep: Creep of concrete is proportional to the content of cement paste or mortar in concretes. 
Ravindrarajah and Tam (1987) found creep of recycled aggregate concretes made with coarse recycled aggregate and natural sand to be 30-60 percent higher than the creep of conventional control concretes.

It can be expected that the creep of recycled concrete could be larger if such concretes were produced with both fine and coarse recycled aggregate (Hansen, 1986).

Drying shrinkage: Wesche and schulz (1982) found drying shrinkage of two recycled aggregate concretes made with coarse recycled aggregate and natural sand to be 40 percent larger than drying shrinkage of control concretes made with conventional aggregates. This is not surprising considering that the recycled aggregate concretes contained 50 percent more mortar than control mixes, and that arying shrinkage increases with the contents of cement paste or mortar in a concrete.

Hansen and Boegh (1985) found that when both coarse and fine aggregates are used, drying shrinkage of recycled aggregate concrete is somewhat higher, perhaps 70 percent higher, than shrinkage of corresponding control concretes made entirely with conventional aggregates.

Tensile and flexural strength: Ravindrarajah and Tam (1985) found the indirect tensile strength of recycled 
aggregate concrete made with coarse recycled aggregate and natural sand not to be significantly different from that of conventional concrete. However, when coarse and fine recycled aggregates were used, the tensile strength of recycled aggregate concretes was as much as 20 percent lower than that of conventional concrete.

Ravindrarajah and Tam (1985) found no significant difference in flexural strength of conventional concrete and recycled aggregate concrete made with coarse recycled aggregate and natural sand.

In Hansen's 1986 report, he refers to two sources which contradict the findings of Ravindrarajah and Tam (1985) and also refers to two other sources which support the findings above.

Abrasion resistance: Hansen and Narud (1983) found Los Angeles abrasion loss percentages ranging from 22.4 percent for coarse recycled aggregate from a high strength original concrete, to 41.4 percent for coarse recycled aggregate from a low strength original concrete.

According to ASTM designation C-33, "standard Specification for Concrete Aggregates", aggregates may be used for production of concrete when the Los Angeles abrasion loss percentage does not exceed 50 percent. crushed stone for road construction purposes is usually required to have L.A. loss values not exceeding 40 percent. 
Hansen (1986) concluded that recycled concrete aggregates produced from all but the poorest quality concrete can be expected to pass ASTM requirements for the L.A. abrasion loss percentage.

Cracking and surface Distress: In the connecticut DOT Final Report for I-84 near Waterbury (1986), it was stated that there were greater amounts of cracks in the recycled section than in the control section. It was suggested that the addition of the crushed, recycled concrete which replaced some of the virgin aggregate, might have raised the average coefficient of thermal expansion slightly and cause increased stresses in the pavement. In this connection, it is has been determined that, under certain conditions, hardened cement may have a coefficient of expansion at least twice that of traprock. The crack development on the recycled section, has, with some exceptions, been at its maximum during the winter seasons.

The largest amounts of distress were found at or near the ends of the sections. There is also end cracking on the control sections, but considerably less pronounced than those on the recycled sections (connDor, 1986).

Friotion resting: From the Connecticut DOT Final Report for I-84 near Waterbury (1986), studies showed a slight 
decrease in the skid resistance number, when comparing the recycled section to the control. There was a pronounced seasonal variation in friction. This is common on heavily traveled bituminous concrete pavements, but was not seen previously on PCC surfaces in the state. skid numbers on bituminous pavements were also found to vary on a short-term basis.

Table 4.3 sumarizes the effects discussed above.

Table 4.3 Effects on Mechanical Properties when Using Recycled Aggregate Instead of Natural Aggregate

\begin{tabular}{|l|l|}
\hline PROPERTY & EFFECP \\
\hline Compressive strength & Reduced (1) \\
\hline Modulus of elasticity & Reduced \\
\hline Drying shrinkage & Increased \\
\hline Creep & Increased \\
\hline Damping capacity & Increased \\
\hline Tensile \& flexural strength & Same or lower \\
\hline Abrasion resistance & Same or lower \\
\hline Cracking and surface distress & Increased \\
\hline
\end{tabular}




\subsubsection{Durability of Recycled concrete}

Frost resistance: Malhotra (1978) and Buck (1977) compared frost resistance of original and recycled aggregate concretes, which were produced with a variety of water-cement ratios. Neither of the two authors found the freeze-thaw resistance of recycled aggregate concrete to be significantly lower than that of corresponding control concretes, and in many cases it was higher.

In the survey from the Minnesota DOT, it was suggested, after having done studies, that fly ash be required for concrete made with recycled concrete aggregates, for dealing with the freeze-thaw resistance.

carbonation, chloride penetration and reinforcement corrosion: It was found that the rate of carbonation of a recycled aggregate concrete made with recycled aggregate from concrete which had already suffered carbonation was $65 \%$ higher than that of a control concrete made with conventional aggregate. Rust was observed after two months on reinforcement bars with $2-3$ cm of cover (Hansen, 1986).

Reinforcement in recycled aggregate concrete may corrode faster than reinforcement in conventional concrete. The increased risk of corrosion can be offset by producing recycled concrete with a lower water-cement ratio than conventional concrete. These conclusions are supported by Rasheeduzafar and Khan (1984). 
Alkali-aggregate reactions: Alkali-silica reaction should not be a problem with recycled concrete pavement in Indiana. One should be aware that it can be a concern with recycled material which contains glass or material of similar composition. These materials should not be used in concrete.

Permeability and water absorption: According to Hansen (1986), the rate of most kinds of concrete deterioration depends on concrete permeability. This is because water absorption is directly related to permeability of hardened concrete, and penetration of water into concrete is required for most deterioration mechanisms to be effective (Hansen, 1986).

Rasheeduzzafar and Khan (1984) found that there will be no significant difference between the water absorption (and thus presumably permeability) of recycled aggregate concretes and corresponding control concretes made with conventional aggregate. This is true when such concretes are produced with water-cement ratios higher (and therefore lower compressive strengths) than that of the original concrete from which the recycled aggregate is derived.

However, the situation is different when recycled aggregate concretes and corresponding control concretes are produced with water-cement ratios lower than that of the original concrete from which the recycled aggregate 
is derived. In such cases, water absorption of recycled aggregate concretes may be up to three times that of the corresponding conventional concretes (Rasheeduzzafar and Khan, 1984). The studies done by Ravindrarajah and Tam (1985) support the previous findings.

It appears that the low strength and correspondingly high water absorption (and thus presumably the high permeability) of the recycled coarse aggregate could be compensated for by producing recycled aggregate concretes with 0.05 to 0.10 lower water-cement ratios than conventional concretes. If the original concrete had been produced with a lower water-cement ratio and thus a higher strength, it is evident that less of a decrease in water-cement ratios of recycled aggregate concretes would have been required to achieve equal water absorption in recycled aggregate concretes and corresponding control concretes (Rasheeduzzafar and Khan, 1984).

Table 4.4, on the next page, summarizes the effects discussed above. 
Table 4.4 Effects on Durability When Using Recycled Aggregate Instead of Natural Aggregate

\begin{tabular}{||l|l|}
\hline PROPBRTY & BPRECr \\
\hline Frost resistance & Increased (I) \\
\hline Carbonation & Increased \\
\hline Chloride penetration & Increased \\
\hline Reinforcement corrosion & Increased \\
\hline Alkali-aggregate reactions & Decreased \\
\hline Permeability and water & Depends upon water-cement \\
absorption & ratio, can have no effect \\
\hline
\end{tabular}

(1) Supported by Minnesota's findings

\subsection{Mixture Design}

In principle, the mixture design of recycled aggregate concrete is no different from the mixture design of conventional concrete, and the same mixture design methods can be used. In practice slight modifications are required.

According to Hansen (1986) the following are modifications that would be necessary.

(1) In order to determine a target mean strength on the basis of a required characteristic strength, a higher standard deviation must be employed when designing a recycled aggregate concrete made with recycled aggregates of variable quality than when recycled aggregate of uniform quality or conventional aggregate is used.

(2) At the design stage, it may be assumed that the free 
water-cement ratio for a required compressive strength will be the same for recycled concrete aggregate as for a conventional concrete when coarse recycled aggregate is used with natural sand. If subsequent trial mixes show that the compressive strength is lower than assumed, an adjustment of the water-cement ratio must be made.

(3) It can be assumed that for the same slump, the free water requirement of recycled coarse aggregate concrete is higher than for conventional concrete.

(4) A maximum recycled aggregate size of 16-19 $\mathrm{mm}$ may be required for reasons of frost resistance.

(5) Because of the higher free water requirements of recycled concrete mixes, the calculated cement contents will be somewhat higher for recycled aggregate concretes than the cement contents for corresponding conventional concretes.

(6) Mixture design must be based on the measured density of recycled aggregate at hand.

(7) Then estimating the ratio of fine to coarse aggregate, it can be assumed that the optimum grading of recycled aggregate is the same as for conventional aggregate.

(8) It is imperative that trial mixes should be made in order to adjust the free water content necessary to obtain the required slump, the water-cement ratio necessary to obtain the required strength, and the ratio between fine and coarse aggregate necessary to achieve the best economy and the cohesion of the fresh mix. Larger deviations can be expected for recycled aggregate concretes than for conventional concretes.

The Iowa DOT, Utilizing Recycled Pavement (1977), determined that the objective of the mixture design was to utilize the total crushed material in such a way so as to obtain a satisfactory portland cement concrete mix which could be placed with a slip form paving machine.

Studies were conducted using materials from a project that was being considered for. recycling, to determine the feasibility of producing a satisfactory concrete. Using this 
material, mixes were made and tested in the laboratory. After evaluation, it was determined that satisfactory results could be obtained and the project concept should continue. A detailed report of their findings can be found in reference 8 (Bergren (Iowa DOT), 1977).

An example of one of the successful mixture designs is shown below, which was used in Iowa on a 1.4-mile section.

\section{Batch Weights :}

Cement

626 lb. per cu. yd.

Crushed concrete-coarse aggregate $1145 \mathrm{lb}$. per cu. yd.

crushed concrete-fine aggregate $613 \mathrm{lb}$. per cu. yd.

Sand-fine aggregate

876 lb. per cu. yd.

\section{Basic absolute volumes :}

Cement

0.118330

Water

0.182217

Air

crushed concrete-coarse aggregate

0.060000

crushed concrete-fine aggregate

0.287754

Sand-fine aggregate

0.154944

0.196755

1.000000

The results of this mixture design were:

Compression

Flexure

$4350 \mathrm{psi}$ at 7 days

702 psi at 14 days

5510 psi at 28 days 


\section{SECTION 5}

END U8ES

\section{INTRODUCTION}

The following section will cover various applications using recycled concrete, the use of concrete fines, and the use of non-concrete components.

\subsection{Applications}

Pavement construction requires a large amount of aggregate during construction and for rehabilitation. crushed concrete can be used in nearly any instance where a normal aggregate would be used, although some may pose quality problems that would preclude their economic use. To date, concrete recycling has been involved primarily with the use of crushed pavement concrete as aggregate in new pavements (Kreijger, 1980).

Buck (1973) determined that recycled concrete can best be used as a substitute for coarse aggregate only. Through the years and after many studies, recycled aggregate has proved its ability to meet swcifications in other uses. The major concern with using recycled concrete in any application is that the test results, with the recycled aggregate, indicate acceptable strength and durability.

The use of crushed concrete as aggregate in new pavement construction is accelerating rapidly. As described below, crushed concrete can be used in many applications for the 
recycled pavement. Examples of the applications are also given.

\subsubsection{Pavement Applications}

- structural pavement

The material passing the $3 / 4$ in. sieve and retained on the \#4 sieve was used as the coarse aggregate for concrete pavement on the 16-mile segment of U.S. 59, in Minnesota. on the John Lodge Expressway in Detroit, large rubble resulted in good yields when it was crushed and processed as specification aggregate for recycling for the new concrete slabs.

\section{- shoulder}

Iowa recycled portland cement concrete for the project on I-680 and used it as the aggregate in the portland cement concrete shoulders. Minnesota used the material passing the $\$ 4$ sieve for shoulder aggregate on U.S. 59. Kansas crushed the existing concrete pavement on I-235 as aggregate for the shoulders, as well as the portland cement treated base (PCTB) and portland cement concrete pavement. 
specifications for bedding and backfilling pipe in a sewer project (Highway Heavy Construction, Aug. 1984).

- soil stabilizer

A low quality cement can improve the behavior of fine grained highly plastic subgrade soils. Normally cement stabilization is most effective in granular soils lacking fines. Because of the low amount of cement being added, the main result obtained in high plasticity soils will be to lower the plasticity index. This is a major benefit in construction areas where heavy traffic must be carried directly onto the subgrade. When the construction is completed, the structure will benefit from a stronger, less moisture-susceptible subgrade (Berger and Carpenter, 1980).

Other applications for non-pavement uses include: Rip Rap, Railroad Ballast, Roofing Granules, Neutralizing Beds, Filtration Beds, Agricultural, Thermal Reservoirs, Lowgrade Cement and Lime, Masonry uses, and Erosion control. Kreijger (1980) lists and describes these end uses for recycled concrete.

\subsubsection{Flowable Fill Application}

When a material is required to be used for a fill in a confined location or with the likelihood of having to be 
removed in the future, flowable fill is the answer. It is a low strength material mixed to a wet, flowable slurry used as an economical fill or backfill material placed by pouring it into the cavity to be filled. It can be placed with minimal effort and no vibration or tamping. Fill may need to be removed when strengths not greater than $150 \mathrm{psi}$, are required. Higher strengths are allowed and, perhaps advisable for other applications. ACI committee 229 calls it "Controlled Low Strength Material" (CLSM); it is not considered concrete.

Flowable CLSM mixtures are an economical alternative due to the saving of labor and time over placing and compacting soil or granular materials. Uses of Flowable Fill include:

1. BACKFILL (Sewer Trenches, Utility Trenches, Bridge Abutments, Conduit Trenches, Pile Excavations, and Retaining Walls)

2. STRUCTURAL FILL (Foundation subbase, subfooting, Floor Slab Base, and Pipe Bedding)

3. OTHER USES (Abandoned Underground Storage Tanks, Wells, Abandoned utility company vaults, Voids Under Pavement, Sewers and Manholes, and to contend with Muddy Conditions)

Recycling of concrete may include airfield paving as well as roads. The recycled material may be used for stabilized or unstabilized base courses, for asphalt concrete, econocrete subbases, or for drainage layers or pipe bedding, according to William Yrjanson (Highway \& Heavy Construction, Feb. 1982). 
Finding the best use continues to be a challenge both for engineers and contractors.

\subsection{Use for concrete Pines}

It has been explained previously that the use of fine recycled aggregate below $2 \mathrm{~mm}(0.08 \mathrm{in.)}$ has a detrimental effect on economy as well as on many technical properties of recycled aggregate concrete. From the point of view of production of recycled aggregate for medium to high-strength concrete, fine recycled aggregate below $2 \mathrm{~mm}(0.08 \mathrm{in}$ ) should be wasted.

Hansen (1986) has suggested other possible uses for crushed concrete fines, which include trickling filters for waste water treatment, poultry grits, acid soil or waste water neutralization, substitution for ground limestone in $\mathrm{SO}_{2}-$ scrubber filters in coal burning power plants, for stabilization of sewage sludge, or as a source of available silica in highly leached lateritic soils. However, it should be kept in mind that the concentration of calcium hydroxide in crusher fines from old concrete is very small, 4 percent by weight at most. Because of the low concentration of calcium hydroxide, use of crusher fines may be uneconomical, even if it can be shown that beneficial effects do indeed exist (Hansen, 1986). 


\subsubsection{Fines in Boil}

The addition of crushed concrete fines may improve both the plasticity index and the grain-size distribution and therefore the engineering properties of clayey soils for earthwork purposes. Such improvements, according to Hansen and Angelo (Nov.-Dec. 1986), go beyond what can be explained by mere mechanical stabilization due to change in grain-size distribution of the soil. It is suggested that the additional improvement which is observed when crushed concrete fines are mixed with clay is due to flocculation and coagulation of colloidal clay materials that react with calcium hydroxide in the crusher fines to form larger grains in the silt fraction. This happens within moments of mixing of the two soils (Hansen and Angelo, 1986).

\subsubsection{Fines in concrete Mix}

Crushed concrete fines consist of both aggregate and fine cement paste particles. When crushed concrete fines were used as fine aggregate in concrete instead of natural sand, study by Ravindrarajah and Tam (1987) revealed the following effects:

(1) Compressive strength at early ages was marginally lower, but with increasing age, the difference in strength became negligible.

(2) The ratio of tensile strength or flexural strength was not affected. 
(3) Modulus of elasticity of concrete at the age of 28 days was reduced by $15 \%$ to $20 \%$.

(4) Compressive strength-pulse velocity relationship was affected considerably and for the same strength the pulse velocity was lower.

(5) Drying shrinkage of concrete was increased by about 408.

(6) Creep of concrete under axial compression was marginally increased.

(7) When pulverized fuel ash was used to replace $10 \%$ by weight of the crushed concrete fines, the detrimental effects of the crushed concrete fines were much reduced.

The Michigan Department of Transportation, Bureav of Highways, provided a document as a supplement to the questionnaire, concerning a special provision for crushed concrete fine aggregate. The following is taken from that special provision.

The fine aggregate which is produced as a by-product of crushing portland cement concrete is prohibited to be used in the following:

\footnotetext{
1. Subbase

2. Embankment under abutments

3. Concrete mixes

4. In conjunction with a geotextile which is used as a filter

5. Granular Material Class I, II or IIA

6. Granular Material Class IIr except where permitted herein
} 
Crushed concrete fine aggregate is permitted to be used, in accordance with the 1990 Standard specifications, in the
following:

1. Embankments except those under abutments

2. Swamp backfill

3. Bituminous mixtures

4. Backfill for non-metallic culvert and sewer pipe without associated underdrains.

The volume of fines in the finished product can be directly related to the care with which the operator of the excavator picked up the broken concrete in the removal process. If any of the clay base adhered to the underside of large pieces, it would persist through the crushing and screening system to appear as fines. If the excavation was done on a rainy day, the wet clay would be especially difficult to remove. Consequently, the amount of fines in the concrete mix can be controlled from the beginning of the project by assuring quality work during the breaking and loading of the concrete rubble to be recycled.

As stated in the Michigan DOT provision (MDOT's questionnaire and supplemental guidelines), there has been concern using concrete made with fine aggregate. Recycled fines are not suitable for use in drainage layers beneath the pavement. Some of the cement material attached to the surface of the fines goes into solution when water percolates through. A precipitate then forms in the drainage structure or on the geotextile fabric used to wrap the drain. Because this plugs the drain, the Michigan DOT no longer allows the use of recycled fines in drainage layers of the pavement base. 


\section{SECTION 6}

QUALITY OP MATERIAL

\section{INTRODUCTION}

The quality of the recycled aggregates will be reviewed by naming the possible contaminants and their acceptable limits. A variety of different tests can be done to assure the quality of the material and will be outlined in this section.

From the responses to the survey, it is evident that most states that recycle concrete judge the quality of the old material to be recycled either by standard specifications for virgin aggregate or based on the performance in the PCC pavement and the service record of the old pavement, or a combination of both. Iowa DOT assesses the quality of the old material based on the quality of the coarse aggregate in the original concrete rubble.

\subsection{Iimits on contaminants}

The problem with contaminants is that if a significant quantity of any contaminant is present in the final product, problems will result in the new pavement. The allowable percentages of contaminants in recycled concrete set by most states is the same as those set for virgin aggregates and must meet standard specifications (Illinois, wisconsin, and Michigan DOTs are examples). Wisconsin also specifies that prior to in-place breaking of the old pavement, the contractor 
is required to remove all asphaltic patches and all joint sealing material. Iowa's specifications limit the amount of base material that can be picked up with concrete rubble.

\subsubsection{D-cracking}

"D"-cracking is a series of crescent-shaped cracks and spalls on the pavement surface which usually start at the intersection of transverse and longitudinal joints and progress from the joints to the center of the panels. In Minnesota, this form of pavement distress is physical in nature and is associated with poor quality aggregates which absorb moisture and deteriorate through freeze-thaw action (Halverson, 1982).

The durability of concrete using aggregates made with concrete subject to D-cracking can be substantially improved over the original concrete by crushing the concrete to a smaller aggregate size. Minnesota Dor research work has indicated that by crushing a pavement with poor quality aggregate to minus $3 / 4$ inch size and by incorporating fly ash into the recycled concrete mix, the resistance of the resulting concrete to freeze-thaw action will be improved (Halverson, 1982).

Illinois has chosen to recycle D-cracked PCC pavement into full-depth asphalt concrete rather than back into PCC pavements due to durability concerns. Iowa also does not recycle rubble from old concrete with proven poor durability problems into new PCC pavement. However, Kansas, Michigan and 
Minnesota have all recycled $D$-cracked pavements and have found no durability problems after several years of service (Love, 1987 and Yrjanson, 1981). Minnesota DOT indicates that the recycled pavement which came from pavements exhibiting Dcracking has performed quite well using fly ash.

\section{$6.1 .2 \mathrm{salt}$}

When pavements, on which salt has been used during the winter months for de-icing purposes, have been considered for recycling the contamination of the pavement due to the chloride content has been questioned. Excessive chloride contents require expensive chloride control measures such as epoxy-coated steel.

Illinois DOT decided to use plain reinforcing steel after it found slightly high chloride content on the I-57 project. Two points supported the decision to use the plain reinforcing steel. First, the fine aggregate was to be washed, which would remove some of the chloride. Second, the crushed concrete would be mixed with other materials and dispersed throughout the recycled concrete, thus minimizing the potential differences that can lead to corrosion (Van Matre and Schutzbach, 1989).

Wisconsin DOT conducted tests on samples from pavements during the project on I-90/94 and found that the concrete contained 4 to $5 \mathrm{lb} / \mathrm{cu} . y d$. of chloride. This could be reason for alarm when considering the use of this material for a reinforced concrete pavement. However, tests of the processed 
material and calculations made with typical batch proportions indicate that chloride in a recycled concrete attributable to the recycled coarse aggregate would be 1.5 to 2 lb./cu.yd. Virgin aggregate sources would contribute approximately 1 1b./cu.yd. chloride in the new concrete mixes (Strand, 1985). Concern about rapid steel corrosion due to the chloride content of the salvaged concrete, as well as from future winter maintenance, led to the decision to epoxy coat all steel in the continually reinforced concrete pavement (CRCP), on I-90/94. The Wisconsin DOT found that the costs which are associated with epoxy coating are expected to be more than offset through increased pavement life (Strand, 1985).

\section{1 .3 others}

The presence of bituminous aggregate particles in recycled aggregate concrete reduces concrete strength in the same way as any other low strength lightweight aggregate particles would reduce concrete strength. Geradu and Hendricks (1985) state that recycled aggregates should not contain more than 1 percent asphalt because of the reduction in compressive strength attributed to the asphalt.

Hansen and Hedegaard (1984) concluded that as long as plasticizing, air-entraining, and retarding admixtures are used in quantities not exceeding manufacturers' recommended dosages, the presence of chemical and mineral admixtures in recycled aggregates has no significant effect on slump, air content, or setting time of fresh recycled aggregate concrete, 
or on compressive strength of hardened recycled aggregate concrete.

The survey which was sent to various states questioned whether they had used recycled aggregate taken from crushed air-entrained concrete, D-cracked, or other problem concrete pavements. The reply concerning D-cracking has been previously addressed. In regards to the others, Illinois has used only air-entrained concrete since 1952. Iowa has recycled problem concrete into base layers without any problems. Connecticut has not recycled problem concrete. other states findings are addressed in the survey.

\section{2 strategy for Quality Assurance}

\section{2 . 1 standard tests}

Prior to determining whether a certain section of roadway could be practically recycled, it is necessary to evaluate the suitability of the old concrete pavement as a source for the recycled concrete aggregate. Samples should be taken from various points along the roadway, and especially areas where contaminants have been found or suspected, and used for laboratory testing to determine the technical feasibility of the roadway.

Some of the standard tests that have been applied throughout the states are:

1. Sodium sulfate soundness test

2. Freeze-thaw resistance 
3. Los Angeles Abrasion test

Other tests done by certain states are for specific contamination problems they have found in their region. For example, the Minnesota DOT (questionnaire) requires freezethaw tests because of the problem with D-cracking which they have found comprises $14 \%$ of all the pavement in the state. However, oregon is not as concerned with the freeze-thaw test because pavements there have not shown any signs of Dcracking, due to the characteristics of the natural aggregates with which the concrete is mixed.

The Illinois DOT requires the standard tests listed above, in addition to a test to find the amount of material passing through the No.200 sieve, and a test to determine the percentage of deleterious materials (e.g. hale, clay lumps, coal and lignite, etc.).

Table 6.1 gives the results of an evaluation which the Michigan DOT has performed to determine whether a certain section of roadway could be recycled. 
Table 6.2 Results of a test for the suitability of old concrete pavement as a source for recycled concrete aggregate (after Hoepfner, 1983) :

\section{Recycled Aggregate}

Soft Particles

Chert Particles

Shale (included in soft)

Los Angeles Abrasid

Unit Aoss 33\%

Specific' Gravity, Bulk

$\begin{array}{cc}\text { Dry } & 2.358 \\ \text { Absorption 23-hr. Soak } & 5.128\end{array}$

Freeze-thaw durability factor

estimate 90

\section{Specification}

$2.3 \% \quad 2.5 \%$

$2.0 \%$ Sum of Soft \& Chert $9.0 \%$ $80 \mathrm{lb} . / \mathrm{ft}^{3}$ Maximum $40 \%$

Minimum $20 \%$

Since a 1980 project Minnesota DOT has used the Concrete Pavement Evaluation system, copes, to track the various distresses associated with concrete pavements within the state (Zoller (MnDoT), 1990).

\subsection{Concluding comments}

Careful planning and design are the first essential parts to assure quality, along with interim and post-construction evaluations. Changes should be made if the interim evaluations show any problems.

Illinois performed an evaluation after finishing the northbound lanes of a project and used the information from these tests to make improvements for the southbound lanes. Based upon the success of the first season of construction, the same procedure was used for the second construction season with minor adjustments. Construction on the southbound lanes 
progressed more smoothly than the construction of the northbound lanes. The learning curve developed during the first season of construction allowed for a more expeditious operation (Van Matre and Schutzbach, 1989).

Evaluations should also be made at the conclusion of each project and should be monitored for the lifetime of the pavement, in order to gain from the results and plan future recycling projects. 
SECTION 7

RI8X AG8EBgLENT AND LIABILITY I8SUEB

\section{INTRODOCTION}

The risks associated with recycling concrete will be examined by looking at liability issues in using recycled concrete aggregates as a highway construction material in the state of Indiana. Most of the states responding to the questionnaire found few risks and liabilities involved with recycling concrete. Illinois suggested that risks would not be a problem if the recycled mixture was equivalent to virgin mixture. Connecticut believed that liability would only be concern if environmental controls are tightened or expanded in the future.

\subsection{Risks}

\subsubsection{Bconomical}

Indiana can expect recycling concrete to be an economic risk for the first several projects. As stated previously, once the contractors and state develop guidelines and have experience with recycling, future jobs can provide economic savings, as illustrated by many other states results.

Economically it would be a risk to neglect the existing shoulders on a project where only the road pavement is being recycled because an unexpected cost will arise when the shoulders have to be repaired or even possibly fail due to the 
heavy construction equipment constantly being moved on them during the recycling process.

Illinois applied a bituminous overlay on the shoulders that were to be used by the construction equipment, before the recycling process began. It was found to be economically feasible and saved the shoulders from cracking and additional distress.

\subsubsection{Technical}

The amount of harmful materials in the old pavement has to be considered because many tests have shown a direct correlation for the performance of poor quality aggregates when they are recycled from old contaminated pavements. Processes have been developed to improve poor quality aggregates to obtain medium-strength recycled aggregate. Beneficiation of aggregate is one available solution when aggregate supplies are scare, but it will add to the cost of aggregate and hence the concrete. Some possible treatments are summarized in Table 7.1. 
Table 7.1

Beneficiation of Aggregates

\begin{tabular}{|c|c|}
\hline Treatment & Removal \\
\hline Crushing & Friable particles \\
\hline Heavy-media separation & Lightweight particles \\
\hline Reverse air or water flow & Lightweight particles \\
\hline Hydraulic jigging & Lightweight particles \\
\hline Elastic fractionation & Lightweight particles \\
\hline washing and scrubbing & $\begin{array}{l}\text { Surface coating, finely } \\
\text { divided materials }\end{array}$ \\
\hline $\begin{array}{l}\text { Selective quarrying, } \\
\text { crushing, and blending }\end{array}$ & $\begin{array}{l}\text { Control or removal of } \\
\text { deleterious components }\end{array}$ \\
\hline
\end{tabular}

\subsubsection{Environmental and Health}

Recycling of portland cement concrete presents both environmental advantages and disadvantages. The advantages are reduction of wastes, reduction of fuel use, reduction of trucking, and reduction of the use of non-renewable resources.

The disadvantages include the intrusion of trucking into locations where this is undesirable, aesthetic concerns, and potential noise and dust control problems.

operation of a crushing and screening plant is always accompanied by the generation of noise and dust. Therefore, 
in the selection of plant location, environmental conditions of the vicinity and legal requirements must be carefuliy studied and necessary countermeasures taken. The early concern about noise and dust problems when crushing concrete with mobile plants in urban areas has apparently been exaggerated (Hansen, 1986). Several contractors have received far less complaints about vibrations from the area surrounding the project when using a resonant pavement breaker for the removal process, as opposed to the conventional drop hammer. obviously the problem of vibrations is usually only a concern when the project is located near an uxban area.

\subsubsection{Political}

As with any construction project, if businesses are located near the project they will complain about being deprived from traffic because of the re-routing that takes place with the rehabilitation of a roadway. This is obviously not a concern when the roadway that needs to be rehabilitated is not near urban areas.

\subsubsection{Time}

Traffic control has probably been one of the major drawbacks to concrete recycling to date. The greatest concern has been the need to close traffic lanes for an extended period of time. This is a problem that has proven to be not so great as originally expected by highway departments that have constructed recycling projects. 


\subsection{Liability}

\subsubsection{Use of Reinforced Concrete}

When recycled aggregate is used for making reinforced concrete, concern has been raised about the corrosion of the steel due to the contaminants in the recycled material. A way of protecting the steel in recycled concrete, as required by some highway departments, is to epoxy coat all the reinforcing steel. Some states have not required epoxy coating if their test shows that the amount of contaminants and if it is below a certain level.

Michigan has found that some recycled coarse aggregates have not provided the same pavement performance as virgin aggregate. "Once cracks appear, the reinforced steel is breaking prematurely due to poor aggregate inter-lock across the crack. Michigan has placed a moratorium on the use of recycled aggregate as coarse aggregate in concrete mainitine pavement until research is completed," according to David smiley of the Michigan DOT (MDOT questionnaire).

\section{2 .2 Bervice Iite}

Life cycle estimates for recycled PCC pavements range from 20 to 35 years. The Michigan Dor predicts that 50 percent of the joint seals and 50 percent of the joints will require replacement during a 35-year life cycle, according to Gerald McCarthy of the Michigan Concrete Paving Association 
and formerly with the state DOT. These estimates are identical for virgin material (Ray, 1985).

Recycled coarse aggregates may be more durable than they were in their original state because the concrete has already gone through years of freeze-thaw cycles, and any resultant cracking would have already occurred. The recycled material may be further strengthened because the portland cement coating on the original aggregate becomes part of the final crushed product, and has greater strength than some of the original aggregate. 


\section{CONCRETE AND OTHER MAMERIALS FROM BUITDINGS}

SECTION 8

BUILDINGS

\subsection{Volume}

It has been estimated that 60 million tons of concrete are demolished each year in the United States (Hansen, 1986). Due to structures no longer fulfilling their functions in an acceptable way, there now are more and more concrete structures in need of demolition. since there are currently a diminishing number of landfills for disposing of the demolition debris, this has caused an increase in interest for demolition recycling. similar to concrete from roadways, buildings may be valuable sources from which recycled concrete can be produced. Figure 8.1 shows a prediction of construction, remodeling, and demolition wastes generated in the U.S.

The weight or volume of wastes from building demolition is rarely measured with any accuracy. Therefore, the outflow wastes can not be directly determined. Instead, demolition wastes are estimated by analyzing the materials that went into the construction of the building. Reinforced concrete buildings are a single time source of concrete, after demolition, which usually constitutes about 75 percent of the total demolition wastes by weight (Ramaswamy et al., 1983). 


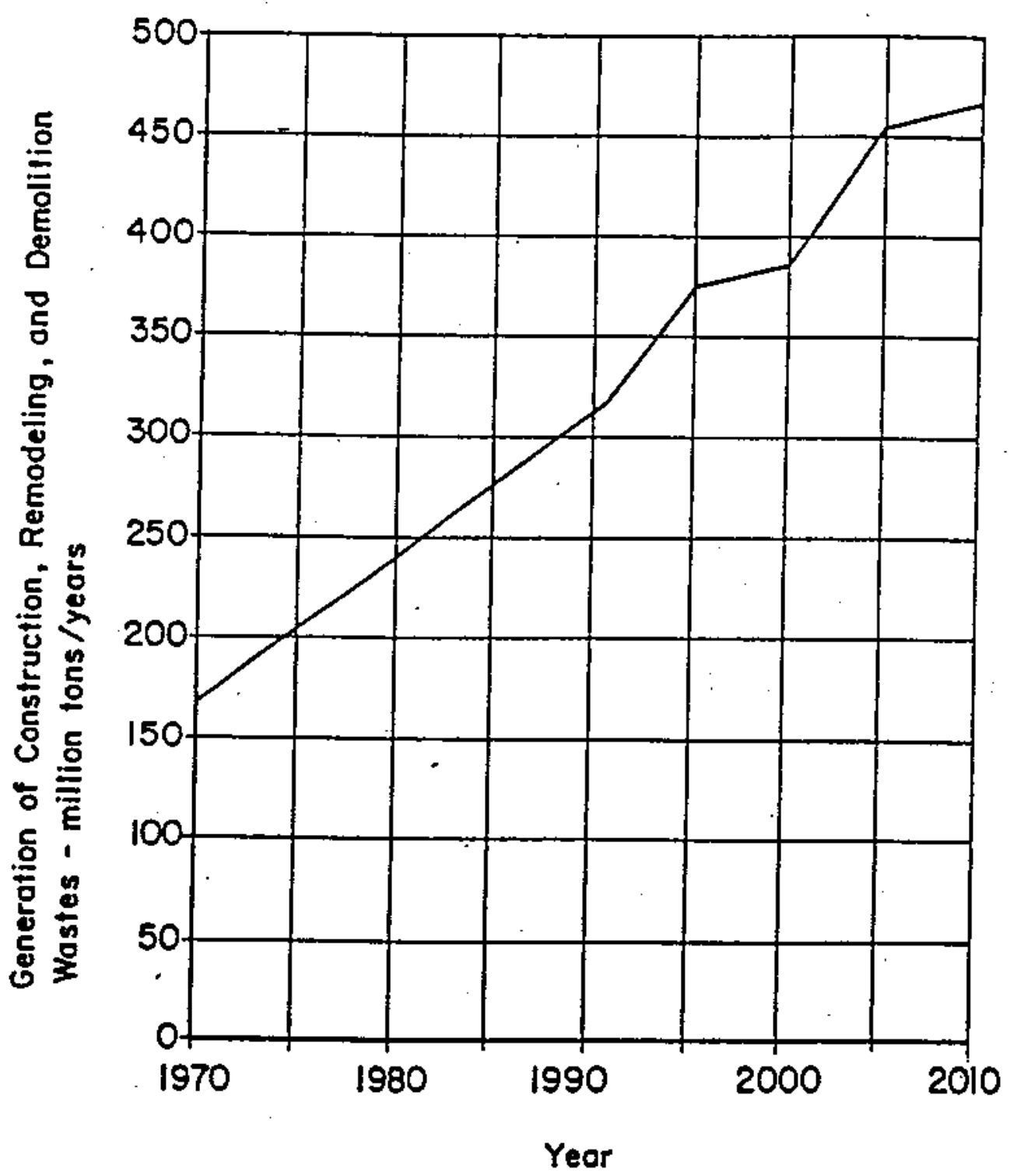

Figure 8.1: Prediction of construction, remodeling, and demolition wastes generated in the United States (from Jones, 1973). 


\subsection{Potential Problems}

\subsubsection{Contaminants}

Concrete from structures to be demolished may have various types of finishes, cladding material, lumber, dirt, steel, and hardware attached to them. It is advantageous if concrete for production of recycled aggregate is freed from foreign matter before demolition.

During the demolition a wide variety of samples can be taken to test the concrete to determine the amounts of contaminants in the material. Reclaimed aggregate from building demolition contains varying quantities of gypsum, glass, tile, plastic, brick, wood and metal. Wood, glass and gypsum are particularly harmful, the former because it is soft and subject to considerable volume changes, the glass and gypsum due to their potential chemical reactivity with portland cement. Due to their relatively low densities, wood and gypsum can be removed by conventional aggregate benefication equipment (civil Engineering, sept. 1981).

\subsubsection{Specifications}

Only three contaminants appear to pose potentially serious durability problems: chlorides, sulfates, and glass. High levels of chloride would necessitate special attention to reinforcement protection. High concentrations of glass would require tests for expansive alkali-silica reactions (Caltrans, 1990) 
Buck (1976) reported that 5 percent gypsum by weight of total aggregate was sufficient to produce harmful internal expansion in concrete made with cement containing over 5 percent $C_{3} A$ when the concrete was moist cured. Expansion was reduced when the specimens were allowed to dry. Neither the use of a cement with reduced $C_{3} A$ content or fly ash was effective in preventing expansion (Buck, 1976).

For ordinary Portland cement, a maximum of 5.2 percent $\mathrm{SO}_{3}$ by weight of the cement should be the specified limit on the basis of the total $\mathrm{SO}_{3}$ content of the cement and aggregate according to Nixon (1978). Like Buck he found that allowing the specimens to dry, reduced the final expansion.

Contaminants should not be a problem in demolition concrete originating from "all-concrete" structures, retaining walls, bridges, etc., unless contamination by chlorides or sulfates occur. Concrete from building demolition wastes may contain gypsum or glass contamination which could lead to harmful long-term expansions. If these problems are recognized, their presence can be monitored and steps taken to counteract their effects (Kreijger, 1980).

For the most part, it appears that existing standards such as those of ASTM, can be applied to coarse aggregates from recycled concrete. Where adequate standards exist, these are referenced in national concrete codes such as, the American concrete Institute code. Little or no change is required to allow the safe use of recycled concrete as course aggregate. 


\subsubsection{Toxio Wasta}

The contaminant that gives the most concern is asbestos because it is considered a toxic waste and should not be combined in other building demolition material. If asbestos is found to be greater than $1 \%$ by weight in the building demolition material, then all of the building material is considered toxic waste and must be disposed of properly, in special landfills (Barnes, 1992). This problem can be solved by removing the asbestos from the building prior to demolition.

\subsubsection{Hazardous waste}

Another contaminant that causes concern when mixed with other demolished material is lead paint, which is considered a hazardous material. This is a new area that is being studied by the Indiana Department of Environmental Management (IDEM). Presently, Indiana does not have any requirements for the amount of lead paint permissible in the demolition material. IDEM has suggested removing any lead paint before the demolition of the building. The amount of lead paint in the material after demolition is believed to be diluted to a small, almost undetectable amount, so that presently it does not warrant the entire amount of material to be considered as hazardous waste, and thus be treated and disposed of as "special waste" (Barnes, 1992). 


\subsection{Applications for concrete}

Applications for concrete from building demolition is similar to the applications for concrete from highways. The reclaimed material can be successfully used to produce, for example, stabilized and unstabilized bases and subbases and fill. Recycled aggregates from structures where high alumina cement has been used, most likely furnaces and kilns, in lieu of Portland cement, should not be used for production of recycled aggregate concrete for structural purposes (Hansen, 1986).

\subsection{Applications for Non-concrete Components}

similar to the steel from the concrete reinforcement from highways, the steel from the demolition wastes can be salvaged and sold. Markets presently exist for scrap iron and steel, aluminum, copper, lead, and glass. However, the market for scrap glass, known as cullet, has up to now accepted mostly clean scrap created within the industry, to which is occasionally added post-consumer bottle cullet. It is not clear how the cullet market would react to the introduction of large quantities of post-consumer window-glass cullet from buildings (wilson et al. 1976).

More recently, Spencer (1990) reports that glass cullet, which would otherwise end up in a landfill, can be processed at 100 tons per hour through a concrete crusher, and sold for $\$ 13$ per ton as fill sand. Waste wood can be processed into 
fuel for cogeneration and also into planter mulch (Spencer, 1990).

other applications of non-concrete components include using building rubble, which is relatively free from contaminants, for use as subbase and subgrade/embankment material. The technical and environmental suitability must be determined prior to its use. The economics of using building rubble will depend upon many factors, including its feasibility for the various applications, processing, crushing to appropriate size, transportation to the location, and the cost of competing natural aggregate (Ahmed, 1991).

\subsection{Demolition Techniques}

Traditional methods of demolition rely on some form of impact to break up a structure and have been used extensively on brick and masonry buildings. A major disadvantage of any impact tool is the high level of noise produced, while the quantities of dust and flying debris are a direct threat to the health and safety of the operators (Lindsell, 1980).

conventional techniques for demolition are sometimes unsuitable for reinforced and prestressed concrete structures. The presence of the reinforcing steel makes the demolition operation more difficult and often more hazardous for the demolition operatives. Consequently, methods of demolition have been introduced in recent years in order to speed up the demolition process and they are aimed at reducing costs, providing better safety and minimum disturbance to the public. 
Traditional methods for demolition include; hand demolition, wire rope pulling, demolition ball, and explosives. The most common and modern method is the hydraulic jaw. other modern methods include; thermic boring, hydraulic burster, diamond saw, diamond core drill, concrete drill, concrete nibbler, abrasive water jets, and the silent drill. More information on these methods can be found in Demolition Technigues for concrete structures (Lindsell, 1980). The entire demolition process usually requires a combination of several of these methods.

Table 8.1 shows the amounts of various materials that can be obtained from wastes due to building demolition, construction and remodeling. 
Table 8.1 Prediction of construction, Remodeling, and Demolition Waste Composition in the United States (after Jones, 1973).

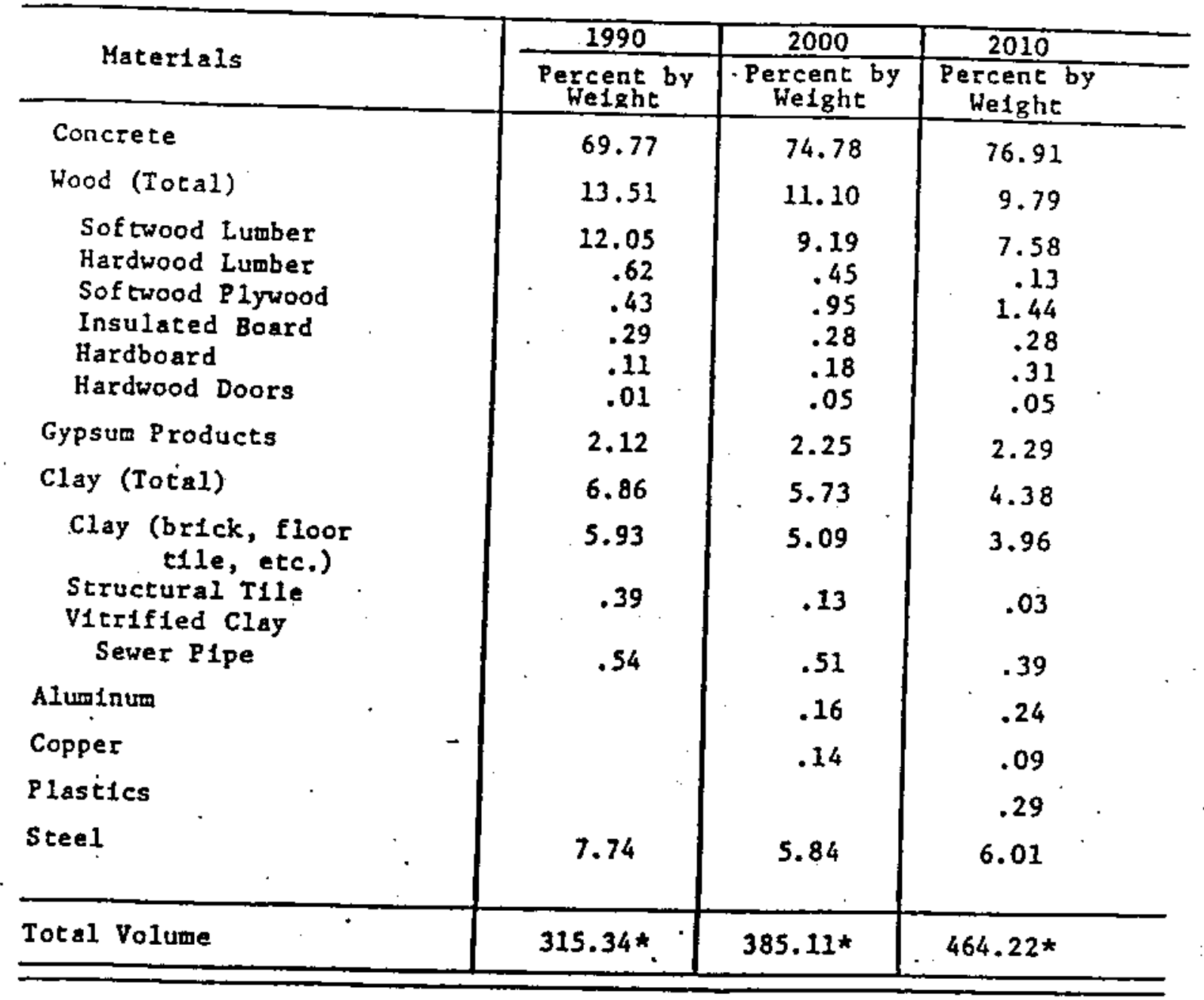

* The total mass are expressed in million tons per year. 


\subsection{Roofing Haterial}

Roofing scrap is a non-biodegradable material that does not belong in a landfill. Roofing waste, which contains roughly 50 percent asphalt, should be treated as a resource rather than, another aisposal problem (Gaudio, 1990).

From the 1992 Roofing Debris Disposal survey, for the Indiana Roofing Contractors Association, it is evident that roofing debris creates a large volume of waste for landfills. The cost of the roofing debris disposal ranged from $\$ 15.00$ to $\$ 32.15$ per ton. According to the three surveys received, the average quantity of debris disposed in Indiana in 1991 was 380 tons. In fact, roofing debris is one of the top ten materials (in volume) contained within landfills today (Ginter, 1991).

A New Jersey firm, Reclaim Inc., appears to have a simple solution by recycling the roofing debris. Only sorted and separated asphalt roofing debris are accepted by a Reclaim facility. Producing savings for customers depends on receiving loads of presorted scrap that contain nothing but asphalt roofing material. Hence, roofing contractors realize the benefits of the far lower tipping fees available from Reclaim than at a landfill (Reclaim will Recycle 100, 000th Ton in October, 1991; from Reclaim, Inc. brochure).

Minnesota used 377 tons of asphalt shingle material to pave eight miles of Minn. Hwy. 25 with the recycled mixture, in June of 1991. That stretch of highway was the first major road in Minnesota to be paved using recycled asphalt shingle material. Organic shingles contain 30 percent asphalt cement, 
which is the most expensive ingredient in the paving mixture (Construction Bulletin, Aug. 1991).

\subsection{Bricks}

Research has been done to justify the use of crushed burnt brick as a substitute for conventional aggregate in concrete construction. High-grade concrete can easily be produced by using brick aggregate. Although this concrete has a lower value of modulus of elasticity, its tensile strength is higher than that of normal weight concrete. Reduced unit weight of brick aggregate concrete is another advantage (Akhtaruzzaman and Hasnat, 1983).

Newman found that brick rubble can be crushed and graded to produce coarse aggregate and fine aggregate which will be entirely suitable for concrete for many building purposes. Concrete made with the aggregate can be safely used in all dry positions, or in many cases, in all positions provided adequate weather protection is provided. 


\section{SECTION 9}

\section{BUMLARY, CONCLUgION, MND RECOMARENATIONS}

\section{1 summary}

This study is a synthesis of the information on the use of concrete recycled from pavements and building rubble for the use in the Indiana Highway system. The information was obtained from a review of published literature and recent unpublished reports. IIn addition, a questionnaire regarding the use of concrete recycled from pavements and building rubble was prepared and distributed to many of the state highway agencies. A majority of the states responded to the questionnaire, giving a summary of their current practices in the use of recycled concrete and their experiences on the technical, economic, and environmental aspects, if they were involved with the practice of recycling concrete.

Section 1 of this report gives the background, states the objectives and describes the research approach. Section 2 through 7 cover concrete recycled from pavements. Section 2 describes the technical feasibility of concrete recycling while section 3 describes the economical feasibility. section 4 details the different engineering properties of the recycled material and describes the mixture design. Section 5 discusses the different applications that the recycled aggregates have been used for. The quality of the recycled material is described in section 6 . Section 7 describes the 
risk and liability issues associated with recycling concrete. The concrete recycled from buildings and its feasibility is discussed in Section 8 . The subsequent sections describe the literature search, results, and a summary of the survey.

\subsection{Conclusion}

Economic considerations are the primary reasons for recycling portland cement concrete (PCC) as aggregate in PCC pavements, although environmental benefits often are derived as well and may become more important in the future. In some areas of the United States there is little supply of virgin aggregate and recycling is the only viable economical solution.

In Indiana, most of the counties have at least one aggregate source. These sources might not always be conveniently located near a project and at some point consideration has to be given to how long these sources will be able to supply the aggregate. Also, if there are aggregate sites within relatively close proximity, the quality of the aggregate in these locations might not be acceptable for the project requirements.

Due to environmental concerns, in some urban areas, it is less expensive and more environmentally acceptable to re-use the PCC than to dispose of it. Therefore, when a PCC pavement will be removed before a new pavement is placed, the project is a prime candidate for recycling. The old pavement is a source of aggregate in the new concrete, and the need and 
expense of disposing the material removed can be eliminated. Further, if the project is large enough for an on-site aggregate plant, the materials' transportation costs are reduced.

All in all it can be expected that the use of recycled aggregate for concrete production will increase in the future as both the demand for road-base material and the price of recycled aggregate is foreseen to decrease.

The following conclusions are made with respect to the engineering properties of recycled concrete:

Using crushed concrete as coarse aggregate did not significantly affect mixture proportions or workability of the mixtures compared with the control mixtures containing natural aggregate.

- When crushed concrete was used as fine aggregate, the mixture was less workable and needed more water and therefore more cement. Substituting natural sand for up to 30 percent of the recycled fine aggregate, improved workability to the approximate levels of a conventional mixture.

- The frost resistance of concrete made from recycled aggregates is not degraded when the original concrete is of a normally good quality.

- Using recycled aggregate did not significantly affect the volume response of concrete specimens to temperature and moisture changes.

- In low-strength concrete, using recycled concrete 
as aggregate is not detrimental to the concrete's compressive strength.

- Using water-admixtures, as well as fly ash, to lower the water content increases the strength of concrete mixtures that contain recycled concrete as aggregate.

Using recycled concrete aggregates instead of natural aggregates in concrete causes:

(1) reduction in compressive strength up to $25 \%$,

(2) reduction in modulus of elasticity up to 308 ,

(3) improvement in damping capacity up to $30 \%$, and

(4) higher amounts of drying shrinkage and creep.

Test results have shown that recycled pavement concrete made chiefly from broken-up and crushed old concrete is as good as concrete made from virgin materials, and sometimes better. The new pavements can be used for many applications. These applications include the use of recycled concrete for structural pavement, shoulder pavement, road surfacing, fill, soil stabilizer, pavement base, subbase material, and econocrete, as well as several other applications which are still being tested.

The use of recycled fine aggregates should be carefully monitored and should not be used for the development of medium to high-strength concrete. Fines should not be used in the subbase, embankment under abutments, and locations surrounding filters. 
The quality of the recycled aggregates can be monitored to assure concrete is not developed with more than negligible contaminants. The recycled concrete has shown to be of acceptable quality and can pass state specifications when mixed proportions are processed properly.

The risks and liability of recycled concrete do not differ very much from those risks and liabilities associated with concrete made with virgin aggregate.

\subsection{Recommendations}

After analyzing other states findings and conclusions, it is recommended that the Indiana Department of Transportation proceed with the implementation of recycling portland cement concrete from pavements and concrete from buildings. The following are offered suggestions for the development of the use of recycling concrete:

- Develop a code of standard specifications, similar to those for virgin aggregate and the concrete Pavement Evaluation System (used by the Minnesota DOT) to assure quality of the recycled material.

- Use a small section (less than 5 miles) that is in need of major rehabilitation to test the process and at the same project use a test section to compare the recycled concrete results with those of conventional concrete.

- Select a location that is distant from a landfill and a virgin aggregate source. 
Monitor the amount of excessive fines (below $2 \mathrm{~mm}$ ) that enters the recycled concrete mixture or do not use excessive fines for recycled pavement.

- Monitor the progress of the recycled pavement by taking samples of the pavement throughout the duration of the project in order to make possible adjustments and evaluate the pavement through its lifetime.

- Test several mixture designs prior to deciding what concrete mixture will be used for the recycled concrete.

- Use all of the tests mentioned in quality assurance to determine the quality of the material.

- Use fly ash in the recycled concrete mixture to improve the workability, and also to improve the quality if using D-cracked pavement.

- Great care should be taken when recycling building materials, to insure that hazardous wastes are not included. 
Table 9.1 Summary of Incentives for Using Recycled
Concrete Pavements

\begin{tabular}{|l|l|}
\hline Technical & Incentives \\
Feasibility & $\begin{array}{l}\text { Can be accomplished easily with modern } \\
\text { equipment. }\end{array}$ \\
\hline Economic & Reduces amount of material filling \\
Feasibility & landfills. Can save money and material. \\
\hline Engineering & Can improve low-strength and D-cracked \\
Properties & concrete when recycled. \\
\hline End Uses & Has several applications besides \\
\hline Buildings & Provide a large source of concrete when \\
\hline Auality of & With admixtures, such as fly ash, \\
Material & recycled concrete can be improved. \\
\hline
\end{tabular}


SECTION 10

\section{INDIANA BEECIFICATIOAB}

The following specifications were provided by Mr. R.K. Smutzer of the INDOT, Division of Materials.

\subsection{Guidelines For Portland cement concrete pavement Recycling Feasibility studies}

This item will involve the obtaining of concrete for testing, preparing the concrete to appropriate gradation, mixing new concrete using the recycled material, casting specimens for testing purposes, and preparing recommendations for the feasibility of using old pavement concrete as aggregate in new concrete.

The elements involved in this feasibility study will be:

1. obtaining concrete

Sufficient amounts of concrete shall be obtained to perform the required tests. The consultant shall provide the traffic protection, the equipment to remove the concrete, the repair/patching materials to repair the pavement, etc.

\section{Preparing Concrete}

The concrete shall be crushed and graded to the appropriate gradation. The absorption and bulk specific gravity shall be determined for the aggregate. 


\section{Kixing New Concrete}

The recycled concrete shall be used as aggregate in the new concrete mixes. The concrete shall be airentrained according to INDOT specifications and meet all required parameters, including maximum w/c ratio, cement content, etc. The plastic concrete parameters for each batch of concrete shall be reported.

4. Casting specimens

Concrete specimens shall be cast to determine the compressive strength, flexural strength, rapid freezeand-thaw durability, and hardened concrete air void system parameters, as a minimum.

Compressive strength * - ASTM C -39

Flexural strength * - ASTM C-78

Rapid Freeze-and-Thaw Durability - Using Indiana Test Method 203-92

Hardened Concrete Air Vold System - ASTM C-457

*Strengths at 3 days, 7 days, 23 days, and 90 days.

\section{Preparing Recommendations}

The results of all testing shall be summarized in a final report with recommendations pertaining to the acceptability of the recycled aggregate, the class and amount of fly ash used in the new concrete, percentage of fine recycled aggregate used, assumptions relative to usage, etc. 
10.2 Recycling Existing Concrete Pavement as coarse Aggregate
in New Concrete pavement The Contractor will be given the option of either recycling the existing concrete pavement as coarse aggregate in the new concrete pavement, or using natural coarse aggregates. If the contractor elects to use the recycling option, the new concrete shall be in accordance with 501 and as follows:

(a) All asphaltic concrete patching and overlay materials shall be removed from the existing pavement prior to concrete pavement removal operations.

(b) The concrete pavement shall be removed in a manner which excludes subgrade and subbase material to the maximum extent practical.

(c) Existing reinforcing steel shall be removed from the existing pavement prior to or during the crushing operation.

(d) The processing equipment shall include a no. 4 screen for the removal of fine material.

(e) The cementitious content of the new concrete shall be 586 pounds per cubic yara or greater.

(f) Fly ash shall be incorporated into the concrete using a 1.25 to $1 \mathrm{fly}$ ash to cement replacement ratio with a 10 percent minimum and 20 percent maximum cement replacement.

(g) The recycled concrete shall be crushed and processed to be in accordance with no. 8 gradation requirements. It shall be handled and stockpiled in such a manner that it 
shall not become contaminated with foreign material.

(h) The fine aggregate used in the new concrete pavement shall be 100 percent natural No. 23 sand.

(i) A water-reducing or water-reducing and retarding chemical admixture from the Department's List of Approved Chemical Admixtures may be used.

The new concrete air content shall be determined by means of volumetric air meter by both the contractor and the Department.

If there is an insufficient quantity of recycled concrete coarse aggregate to complete the new concrete pavement, the contractor shall supply natural coarse aggregate necessary to complete the pavement.

The reinforcing steel, dowel bars, and dowel baskets removed from the existing concrete pavement shall become the property of the contractor and shall be removed from the project site.

\subsection{Recycling Existing Concrete Pavement as coarse Aggregate in Bituminous Concrete and Compacted Aggregates}

The contractor will be permitted to reclaim and process removed concrete pavement into aggregates which may be used in bituminous mixtures and compacted aggregate provided the specified gradations are achieved.

Such processing shall be limited to material obtained within the project limits. All reinforcing steel shall be removed from the processed aggregate. The minus No. 4 material shall have a minimum sand equivalent of 80 percent. 
Tests for sand equivalent shall be in accordance with ASTM D 2419. Coarse aggregate shall be in accordance with the deleterious percentage requirements of $903.02(\mathrm{~b})$. When the aggregate to be produced is compacted aggregate for base, type $P, 53$, the percent of fines passing the No. 200 sieve shall not exceed 5 percent. When the aggregate to be produced is compacted aggregate for undercut backfill size No. 53, modified, the percent of aggregate passing the No. 200 sieve shall be between 5 and 15 percent and the plasticity shall not exceed 7 . 
SECTION 11

\section{REFERENCE8}

\subsection{Iiterature Bearch}

The main searching method in gathering information through articles was achieved by using key word searches through data basis at libraries throughout the country. In the initial search approximately 100 articles were retrieved relating to recycling concrete. From the references of the initial articles, a second generation search was completed. The articles consisted of one page summaries, government documents, general articles, published books, and thesis'. A patent search was attempted, however no information was found.

After the second search was completed, additional unpublished reports were obtained and the total amount of references was over 200 .

The references are contained in a box and can be obtained from Professors Scholer and Cohen's office at purdue University.

\subsection{References cited}

1. Ahmed Imtiaz. Use of Waste Naterials in Highway Construction: FHWA-IN-JHRP-91-3. (Joint Highway Research Project).

2. Akhtaruzzaman, Ali A; Hasnat, Abul. "Properties of Concrete Using Crushed Brick as Aggregate". Concrete International; Feb. 1983; p. 58-63.

3. "Alkali-Reactive Aggregates Recycling in New Pavement". Highway \& Heavy construction; Feb. 1987; p. 104-105. 
4. Anon. "Pavement Recycling Guidelines for Local Government": Public Works; Jan. 1989; Vol. 120 No. 1 , p.
52-56; ISSN: 0033-3840.

5. Anon. "Pavement Recycling Guidelines for Local Government". Public Works; Feb. 1989; Vol. 120 No. 2, p.
63-66.

6. Arnold, C.J. "Recycling Concrete Pavements". Concrete construction; March 1988; Vol. 33 No. 3, p. $320-324$.

7. Barnes, Tracey. "Personal communication". Indiana Department of Environmental Management, office of Solid and Hazardous Waste; (April, 1992).

8. Bergren, Jerry v. Portland cement Utilizing Recycled Pavement; Jan. 1977; (Iowa Department of Transportation).

9. Buck, Alan D. "Recycling concrete as a source of Aggregate" . ACI Journal; May 1977; p. 212-219.

10. Bye, G.C. Portland Cement Composition Production and Properties; 1983; ISBN: 0-08-029964-4.

11. Caltrans (1990), "Caltrans Response to AB 1306, "Memorandum of Caltrans, office of Transportation Materials and Research, Dated October 15, 1990", Sacramento, CA; (unpublished), PP4.

12. Chase, G.W.: Lane, J. "Rehabilitation of Portion of Interstate 35 with Pavement Inlay Using Recycled Concrete for subbase" . 3ra International conference on concrete Pavement Design and Rehabilitation: Apr. 23-25, 1985; Purdue University; Apr. 1985; p. 649-655; ISBN: 0182-
3329 .

13. "Concrete Freeway Recycled in 13 Weeks in Michigan". Highway \& Heavy construction; Apr. 1984; p. 56-57.

14. "Concrete Interstate Widened and Recycled Under Traffic". Highway \& Heavy construction; Sept. 1984; p. 42-43.

15. "Concrete Recycling to Grow as Interstates Age". Highway \& Heavy Construction; Feb. 1982; p. 59-62.

16. "CPM Guides Freeway Recycling". Highway \& Heavy Construction; Oct. 1984 ; p. 48-49.

17. "Fast Break-Up and Crushing Shortens Recycling", Highway \& Heavy Construction; Apr. 1986; p. 48-49.

18. Forster, stephen W. "Recycled Concrete as Aggregate". Concrete International Design and Construction; Oct. 1986; Vol. 8 No. 10 , p. 34-40; ISSN: 0162-4075. 
19. Frondistou-Yannas, S.A.; Itoh, Taichi. "Economic Feasibility of concrete Recycling". Journal of the Structural Division; Apr. $1977 ;$ p. 885-889.

20. Gerardu, J.A.; Hendricks, C.F. "Recycling of Road Pavement Materials in the Netherlands". The Hague; 1985.

21. Ginter, Craig. "Roofing Debris Initiative". November 20, 1991.

22. Halverson, A.D. "Recycling Portland cement concrete Pavement". Transportation Research Record \#853; 1982; p. 14-17.

23. Halverson, A.D. Recycling Portland cement concrete Pavements - Worthington, Minnesota. Federal Highway Administration; Feb. 1982; FHWA-DP-47-3. (Demonstration Project No. 47).

24. Hansen, Torben C.; Hedegard, Soren E. "Properties of Recycled Aggregate Concretes as Affected by Admixtures in original Concretes". ACI Journal; Jan.-Feb. 1984; p. 2126.

25. Hansen, Torben $C$. "Recycling Aggregate and Recycling Aggregate Concrete-Second state-of-the-Art Report Development 1945-1985". Mater Struc N; May-June 1986; p. 201-246.

26. Hansen, Torben C.; Angelo Jorgen, w. "Crushed Concrete Fines Recycled for Soil Modification Purposes". ACI Journal; Nov.-Dec. 1986; p. 983-987.

27. Hansen, Torben C.; Boegh, Erik. "Elasticity and Drying Shrinkage of Recycled-Aggregate Concrete" . ACI Journal; Sept.-Oct. $1985 ;$ p. 648-652.

28. Hansen, Torben C.: Narud, Henrik. "Strength of Recycled Concrete Made from Crushed Concrete Coarse Aggregate". Concrete International; Jan. $1983 ;$ p. 79-83.

29. Hoepfner, R.P. (P.E.). "Recycling Portland cement Concrete Pavements-Macomb County Michigan". Federal Highway Administration: FHWA-DP-47-4; June 1984; (Demonstration Project No. 47).

30. Jones. "Figure 1, p. 10; Table 3, p. 11"; 1973; predictive criteria for construction/Demolition solid Waste Xanagement; Technical Report N-14; December 1976.

31. Kreijger, Pieter c. Adhesion Problems in Recycling of Concrete; 1980 ; ISSN: 0-306-40817-1. 
32. Lane, Kelth R. "Recycling Portland cement Concrete Pavements - Waterbury, Connecticut" Federal Highway Administration FHWA-DP-47-2; Jan. 1982 ; (Demonstration Project No. 47)

33. Lindsell, P. "Demolition Techniques for structures". Adhesion Problems in Recycling of concrete; 1980; ISSN:

34. Malhotra, V.M. "Recycled Concrete - A New Aggregate". Canadian Journal of Civil Engineering; March 1978; Vol.

35. McCarthy, G.L.; MacCreery, W.J. "Michigan Department of Transportation Recycles Concrete Freeways". 3rd International Conference on Concrete pavement Design and Rehabilitation: Apr. 23-25, 1985; Purdue University; Apr.

36. Munn, Walter D. "Recycled Concrete is There Business". Highway \& Heavy Construction; March 1988; p. 62-64.

37. "New Breakers Team Up on Concrete Slab" . Highway \& Heavy Construction; Feb. 1985; p. 44-45.

38. Newman, A.J. "The Utilization of Brick Rubble from Demolished Shelters as Aggregate for Concrete". Journal of the Institute of Nunicipal Engineer; Vol. 73 No. 2, p.

39. Nixon, P.J. "Recycled Concrete as an Aggregate for Concrete -a Review". Mater Struct N; Dec. 1978; p. 371-
378 .

40. "Old Concrete Recycled as Rock for New Pavement". Highway \& Heavy Construction; Feb. 1988; p. 30-32.

41. Ong, K.C.G.: Ravindrarajan, R. Sri. "Mechantcal Properties and Fracture Energy of Recycled-Aggregate Concretes". Soc, for Experimental Mechanics; June 1987; p. 150-158.

42. "Pavement Breaker speeds Construction of New Runway". Highway \& Heavy Construction; Feb. $1984 ;$ p. 68 .

43. Ramaswamy, S.D.; Murthy, C.K.; Nagaraj, T.S. "Use of Waste Materials and Industrial By-Products in Concrete Construction". Newconcrete Materials; 1983 ; p. 137-172.

44. Rasheeduzzafar; Khan, Asfahanullah. "Recycled Concrete Source for New Aggregate". Cement, concrete and Aggregate; 1984 ; vol. 6 No. 1 , p. 17-27. 
45. Ravindrarajah, R. Sri; Loo Y.H.; Tam C.T. "Recycled Concrete as Fine and Coarse Aggregates in concrete". Magazine of Concrete Research; Dec. 1987 ; Vol. 39 No. 141, p. 214-220; ISSN: 0024-9831.

46. Ravindrarajah, R. Sri; Tam, C.T. "Properties of Concrete Made with crushed Concrete as coarse Aggregate". Magazine of Concrete Research; March 1985; Vol 37 No. 130, p. 29-38.

47. Ravindrarajah, R. Sri; Tam, C.T. "Recycling concrete as Fine Aggregate in Concrete". International Journal of Cement composites and Lightwejght concrete; Nov. 1987; Vol. 9 No. 4, p. 235-241; ISSN: 0262-5075.

48. Ray, Gordon K. "New Pavement From old concrete". Civil Engineering/ASCE; May 1985; p. 56-58.

49. "Recycling Concrete Materials". Civil Engineering; Sept. 1981; p. 33-37.

50. Roth, Larry. "Concrete Recycling - The Way of the Future". Highway \& Heavy Construction; Feb. 1984; p. 3439.

51. Rukavina; Mitchell. "Portable Crusher Recycles Concrete, Removes Rebar". Rock Products; June 1989; p. $21,68$.

52. Rukavina: Mitchell. "Recycling: Grab the Trend Now". Rock Products; March 1989; Vol. 92 No. 3, p. 54, 57; ISSN: 0035-7464.

53. Snell, D. "New Crusher System for Working with Mobile Plants". Journal of Mines; Nov. 1988; Vol. 36 No. 11, p. 525-527; ISSN: 0022-2755.

54. Strand, D.L. "Design for Quality, concrete Pavement Rehabilitation and Recycling on Wisconsin's Interstate Highways". 3rd International Conference on concrete Pavement Design and Rehabilitation; Apr. 23-25 1985; Purdue University; Apr.. 1985.

55. Van Matre, F.R.; Schutzbach, A.M. "Illinois' Experience with a Recycled Concrete Inlay". 4th International Conference on Concrete Pavement Design and Rehabilitation; Apr. 18-20 1989; Purdue University; Apr. 1989 ; P. 625-639; FHWA-RD-89-209.

56. "V-Float Beats specifications for smooth Recycled Pavement". Highway \& Heavy Construction; May 1985; p. 42-44. 
57. Weschek, Shulz R. "Beton Aus Aufbereitetem". Altbeton Technologie und Eigenschafter; Feb. and Mar. 1982; Vol. 32 No. 2 and 3 .

58. Yoshikane, T. "The Instances of concrete Recycled for Base Course Materials in Japan". Demolition Methods and Practice; Nov. 1988; p. 756-765.

59. Yrjanson, W.A. "Recycling Portland cement concrete". Concrete Pavement Design, 2nd International conference; Apr. 14-16 1981; Apr. 1981; p. 431-434; Purdue University.

60. Zoller, T. "Update on Performance of 10 Year old Recycled D-Cracked Pavement" . National D-Cracking Workshop; May 2-3 1990; Lenexa, Kansas. 


\subsection{Other References (Not Cited)}

1. Adans, Bruce. Ohio, Sand, Gravel Producer Recycles Broken Concrete. Pit \& Ouarry: Feb. 1988; Vol. 80 .

2. "Airport Pavements Totally Recycled". ENR; October 14, 1982; p. 28-29.

3. Akhtaruzzaman, Ali A; Hasnat, Abul. "Shear and Flexural Behavior of Brick-Aggregate Concrete Beams Without Wed Reinforcement". ACI Journal; Mar.-Apr. 1986; p. 284-289.

4. Anon. "Recycling of Materials, Selected Papers From the Fifth International Recycling Congress". Conservation \& Recycling; 1987 ; Vol. 10 No. 2-3, p. 53-190; ISSN: 03613658 .

5. "Asphalt Roof shingles Become Part of Minn. Hwy. 25". Construction Bulletin; Aug. 1991.

6. Austin, Teresa. "Building Green" Civil Engineering; Aug. 1991; p. 52-54.

7. Bauchard, M. "The Use in Roads of Aggregates Made From Demolition Materials". Demolition Methods and Practice; Nov. 1988 ; p. 719-725.

8. Britson, Ralph; Calvert, George. Recycling of Portland Cement Concrete Roads in Iowa; 1977; (Iowa Department of Transportation) .

9. Brock, J.D.; Shaw, D. From Roofing Shingles to Roads.

10. Buck, A.D. "Recycled Concrete". U.S. Army Engineer Waterway Station Miss; May 1972; AEWS-MISC PAPER-C-72-14.

11. Buck, A.D. "Recycled Concrete" Highway Research Record \#430; 1973 ; p. 1-8.

12. Buck, A.D. "Recycled Concrete as a source of New Aggregate" - U.S. Army Engineer Waterway Experiment Station Miss, A Apr. 1976; WES-MP-C-76-2.

13. Buck, A.D. "Use of Recycled Concrete as Aggregate"; U.S. Army Engineer Waterway Experiment station; Dec. 1972; WES-MP-C-72-73.

14. Burrell, Steve. "High-Tech Pavement Recycling". Public Works; Dec. 1984 ; p. 50-51.

15. Busch, Christian. "Crushed Concrete Used as Basecourse Material on Runway 04R-22L at Copenhagen Airport". Demolition Methods and Practice; Nov. 1988; p. 766-774. 
16. Chatterjee, samer. Predictive criteria for Construction/Demolition solid Waste Management; Dec. 1976; Technical Report N-14.

17. "Concrete Pavement Crushed, Recycled for Replacement Slab". Highway \& Heavy Construction; Jan. 1985; p. 5658 .

18. "Concrete Pavement Recycled". Construction; Sept. $1976 ;$ p. 30-31.

Highway \& Heavy

19. "Concrete Runway Recycled as Asphalt Runway". Highway \& Heavy Construction; Sept. 1984; p. 44-46.

20. "Concrete-Pavement Recycling Could slash Rehab Costs 30\%". Civil Engineer/ASCE; July 1981.

21. "Corrosion of steel and Other Materials Embedded in Concrete". ACI Journal; Dec. 1977; p. 589-596.

22. "Crushing Converts Rubble Into Subbase Aggregates". Roads and Streets; May 1971; p. 44-45.

23. Darter, Michael I. "Megatrends for Pavement $4 R$ and Maintenance". ACI Journal; June 1991; Vol. 13 No. 6, p. $64-65$.

24. De Pauw, C.: Rousseau, w. "Equipment Performance and Mixing Techniques". Building Research and practice; MayJune 1986; Vol. 19 No. 3, p. 164-169; ISSN: 0182-3329.

25. "Faulty concrete surfaces on several california Projects". ENR; Nov. 20, 1980; p. 13 .

26. Forster, Stephen $W$. "The Use of Recycled Portland cement Concrete (PCC) as Aggregate in PCC Pavements". public Roads; Sept. 1985 ; Vol. 49 No. 2 , p. 37-42.

27. "Frequent Flier Job Succeeds". ENR; June 15, 1988.

28. Frondistou-Yannas, S.A. "Recycled concrete as New Aggregate". Progress in Concrete Technology; p. 639-684.

29. Frondistou-Yannas, S.A. "Waste Concrete as Aggregate for New Concrete". ACI Journal; Aug. 1977; p. 373-376.

30. Fujii, Tadayoshi. "strength and Drying shrinkage Behavior of Concrete Using Concrete crushed Aggregate". Demolition Methods and Practice; Nov. 1988 ; p. 660-669.

31. Gaudio, M.M. (Asphalt Recovery systems, Inc.). [Letter to Kandhal, P.S.]; Jan. 9, 1990. 8. 

32. Gluzhge, P.I. "Concrete and cement". The Engineers
Digest; p. 330.

33. Goldstein, Gary, "Pavement Recycling stopgap or Remedy?" Civil Engineering/ASCE; Sept. 1984; p. 54-57. 34. Green, Peter. "Highways: The Second Time Around". ENR;
Feb. 11, 1988; p. 38-39.

35. Grimaldi, A.F. "Pavement Rehabilitation Evaluating, Recycling, Extending Useful Life". Annals of the New York Academy of Sciences: 1984 ; Vol. 431 , p. 215-227;

36. "Guide for Use of Normal Weight Aggregates in Concrete". Concrete International; Nov. $1986 ;$ p. 56-66.

37. "Guidelines for Recycling Pavement Materials"; NCHRP Report 224; 1980; ISSN: 0077-5614 (Highway Research Program Report 224, Transportation Research Board, National Research Council).

38. Hansen, T.C.; Narud H. "Recycled Concrete and silica Fume Make Calcium Silicate Bricks". Cement and concrete Research; 1983 ; Vol. 13; p. 626-630.

39. Hansen, T.C.; Narud, H. "Recycled Concrete and Fly Ash Make Calcium Silicate Bricks". cement and Concrete Research; 1983; Vol. 13, p. 507-510.

40. Hansen, Torben C. "Recycled Concrete Aggregate and Fly Ash Produce Concrete Without Portland Cement". Cement and Concrete Research; May 1990; Vol. 20 No. 3, p. 355356; ISSN: 0008-8846.

41. Hansen, Torben C. : Marga, Marius, "Strength of recycled Concrete Made from Coarse and Fine Recycled concrete Aggregates". Demolition Methods and Practice; Nov. 1988; p. 605-612.

42. Hasaba, S.; Kawamura, M.; Torii, K.: Takemoto, K. "Drying Shrinkage and Durability of Concrete Made of Recycled Concrete Aggregates". Transactions of The Japan Concrete Institute: 1981; Vol. 3, p. 55-60.

43. "Health Assessment for Port Washington Landfill". New York State Department of Health; June 1989; PB90-140435.

44. Heck, W.J. "Study of Alkali-silica Reactivity Tests to Improve Correlation and Predictability for Aggregates". Cement, Concrete, and Aggregate; Summer 1983 ; Vol. 5 No. 1, p. 47-53. 
45. "Highways: The Second Time Around". ENR; Feb. 11, 1988; p. 38-39.

46. Howard, Patrick D. "Microwave Recycling of Reclaimed Asphalt Pavement". Public Works; Oct. $1989 ;$ p. 53-55.

47. Ikeda, T.; Yamane, S.; Sakamoto, A. "Strengths of Concrete Containing Recycled Concrete Aggregate". Demolition Methods and Practice; Nov. 1988 ; p. 585-594.

48. Jakobsen, Jens Bjorn; EIle, Morten. "On-Site Use of Regenerated Demolition Debris". Demolition Methods and Practice; Nov. $1988 ;$ p. 537-546.

49. Kaga, H.; Kasai, Y.; Takeda, K.; Kemi, T. "Properties of Recycled Aggregate from Concrete". Demolition Methods and Practice; Nov. 1988 ; p. 690-697.

50. Kakizaki, M. Dr.; Harada, M. ; Soshiroda, T. Dr.; Kubota, S. Ikeda, T.; Kasai, Y. Dr. "Strength and Elastic Modulus of Recycled Aggregate concrete". Demolition Methods and Practice; Nov. 1988 ; p. 565-574.

51. Kakizaki, Masayoshi; Harada, Minoru. "Manufacturing of Recovered Aggregate Through Disposal and Recovery of Demolished Concrete structures". Demolition Methods and Practice; Nov. 1988 ; p. 699-709.

52. Kakizaki, Masayoshi; Harada, Minoru; Isokazu Nishikawa. "Study of a Method for crushing concrete with Microwave Energy". Demolition Methods and Practice; Nov. 1988 ; p. 290-299.

53. Kalin, Zev. "Canada Targets C \& D Debris". Biocycle; Jan. 1991; Vol. 32 No. 1, p. 35-36; ISSN: 0276-5055.

54. Kasai, Y. "Construction Material Waste Problems and Recycling - Concrete and Coarse Aggregate Recycling". Yetals and Technology; Oct. 1990; Vol. 60; ISSN: 10; p. 37-43.

55. Kasai, Y.; Kisaka, M.; Yanagi, K. "Durability of Concrete Using Recycled coarse Aggregate". Demolition Methods and Practice; Nov. $1988 ;$ p. 623-632.

56. Kasai, Y.: Rousseau, E.; Lindsell, P. "Outline of Various Demolition Methods and Their Evaluation". Demolition Methods and Practice; Nov., 1988; p. 1-11.

57. Kashino, N.; Takahashi, Y. "Experimental studies on Placement of Recycled Aggregate Concrete". Demolition Methods and Practice; Nov. 1988 ; p. 557-564. 
58. Kawai, Toru; Natanabe, Morishige; Nagataki, Shigeyoshi. "Preplaced Aggregate Concrete Made From Demolished Concrete Aggregates". Demolition Methods and Practice; Nov. 1988 ; p. 680-689.

59. Kawamura, M.; Torii, K. "Reuse of Recycled Concrete Aggregate for Pavement". Demolition Methods and Practice; Nov. $1988 ;$ p. 726-735.

60. Kennedy, J.: Clark, A.J. Reconstruction Trials for East Sussex county council of Mix-In-Place Recycling with Cement and Glass-Fiber-Reinforced surface Dressing; March 1986; ISSN : 0-7210-1344-9.

61. Kikuchi, Masafumi; Mikai, Takeshi; Koizumi, Haruo. "Properties of Concrete Products Containing. Recycled Aggregate". Demolition Methods and Practice; Nov. 1988 ; p. 595-604.

62. Klemens, Thomas L. "County Puts New Twist on In-Place Recycling". Highway Heavy Construction; Sept. 1989; p. 40-42.

63. Klemens, Thomas I. "Hot In-Place Recycling Adds 15 years to Asphalts Life". Highway \& Heavy Construction; p. 5657 .

64. Klemens, Thomas L. "Interstate Slabs Recycled for Base". Highway \& Heavy Construction; Mar. 1990; p. 32-24.

65. Knutson, M.J.; Riley, Randell c. "Concrete Paving Hits the Fast Track". Highway \& Heavy Construction; Sept. 1987; Vol. 130 No. 9, p. 80-83; ISSN: 0362-0506.

66. Kobayashi, Shigetoshi; Kawano, Hirotaka. "properties and Usage of Recycled Aggregate Concrete" . Demolition Methods and Practice; Nov. 1988 ; p. 547-556.

67. Konno, K. "Abrasive Waterjet Method for Cutting Reinforced concrete structures". Demolition Methods and Practice; Nov. 1988 ; p. 176-186.

68. Krass, K.; Rehbein, K.; Blanke, H. "Use of Industrial Byproducts and Recycling Building Material for Road Construction: Results of Inquiry". Stresse und Autobanh; Sept. 1986; p. 326-330.

69. Kumar, V.; Roy, B.N.: Sai, A.S.R.B.N. "Brick-Ballast and Recycled-Aggregate Concrete" . Indian Concrete Joumal; Feb. 1988 ; Vol. 62 No. 2, p. 85-87; ISSN: 0019-4565.

70. Lindse11, P.: Buchner, S.J. "Monitoring Demolition of Prestressed Concrete". Building Research and Practice; May-June 1986; p. 160-163. 
71. Love, Rosemary M. "State DOT Experiments with Concrete Pavement Recycling". Public Works; June 1987; Vol. 188 no. 6, P. 83-85; ISSN: 0033-3840.

72. Malhotra, V.M. "Use of Recycled concrete as a New Aggregate". Mineral Sciences Laboratories; May 1976; ISBN : 0-660-00622-0.

73. Marek, C.R. "Look at Processed Rubble - It's Valuable Source of Aggregates". Roads and Streets; Sept. 1971; p. 82-85.

74. Marek, C.R. "Supplemental Aggregates for Construction". Journal of Naterials; March 1972; Vol. 7 No. 1, p. 50-54.

75. "Market survey - Part 2 Concrete Technology". Betonwerk Fertigteil-Technink; Nov. 1988 ; Vol. 54 No. 11, p. 105-

76. Marks, Vernon J. "Recycled Portland Cement Concrete Pavement in IOWA". Iowa DOT Project HR-506; Iowa Department of Transportation; Nov. 1984.

77. Matsushita, Yusuke. "Partial Dismantling of a Hospital by Water Jet System". Demolition Kethods and Practice; Nov. 1988; p. 187-196.

78. Molin, Christer. "Controlled Blasting of Concrete". Building Research and Practice; May-June 1986; p. 170174 .

79. Morlion, D. "Demolition Waste of the "Zandvliet" Lock as Aggregates for Concrete". Practice; Nov. 1988; p. 709-718.

80. Mukai, Takeshi; Kikuchi, Masafumi. "Properties of Reinforced Concrete Beams Containing Recycled Aggregate". Demolition Methods and Practice; Nov: 1988; p. 670-679.

81. Mulheron, M. "The Recycling of Demolition Debris: Current Practice, Products and Standards in the United Kingdom" - Demolition Vethods and Practice; Nov. 1988 ; p. 510-519.

82. Mulheron, M.; O'Mahony, M. "The Durability of Recycled Aggregates and Recycled Aggregate Concrete". Demolition Methods and Practice; Nov. 1988; p. 633-642.

83. Munro; Robert R. "Urban Mining: Recycling Concrete and Asphalt" Mining Engineering; July 1984; p. 734-736.

84. "New Findings with Regard to the Processing". Betonwerk Fertigteil-Technik; oct. 1988; Vol. 49 No. 10, p. 634- 
85. Nishibayashi, S.: Yamura, K. "Mechanical Properties and Durability of Concrete from Recycled Coarse Aggregate Prepared by Crushing Concrete". Demolition Methods and Practice; Nov. 1988 ; p. $652-659$.

86. Normile, Dennis; Post, Nadine M. "Concrete Recycler Improves Productivity with concrete Pulverizer". Concrete Debris Update

87. Oberlender, Garold D. Earthmoving and Heavy Eguipment. Equipment Requirements for Concrete Recycling; suprenant, Bruce A. : Whelan, Michael; $1986 ;$ p. 52-65; ISBN: 0-87262-
548-6.

88. Offermann, H. "Prospects for Recycling Building Debris" . Strassen und Tiefbau; Jan. 1987; Vol. 41 No. 1 ; ISSN: 0039-2197.

89. Paulsen, Stroup-Gardiner, Epps. "Recycling Waste Roofing Material in Asphalt Paving Mixtures". "Transportation Research Record. 90. "Pavement Recycling". Civil Engineering; Nov. 1984 ; $p$.
34-39.

91. "Planer Chews Old Pavement Into Reusable Base chips". ENR; March 27, 1973; p. 24.

92. Puckman, Knud; Henrichsen, Anders. "Reuse of Concrete Pavements". Demolition Methods and Practice; Nov. 1988;
p. 746-755.

93. "Quick Runway Recycling Wins Performance Bonus". Highway \& Heavy Construction; Feb. 1984; p. 58-59.

94. Ramachandran, V.s. Waste and Recycled Naterials in Concrete Technology; Oxford, New York; Pergamon Press; 1983.

95. Ravindraxajah, R. Sri; Tam, C.T. "Methods of Improving the Quality of Recycled Aggregate concrete". Demolition Methods and Practice; Nov. 1988; p. 575-584.

96. Ray, Gordon K. "Recycled Concrete-Savings Potential". American Transportation Builder; Jan.-Feb. 1978; p. 1214.

97. Rebeiz, K.S.; Fowler W.D.; Paul, D.R. "Making Polymer Concrete with Recycled Pet". Plastics Engineering; Feb. 1991; p. 33-34. 98. Reclaim wiIl Recycle 100,000th Ton in October; sept. 3, 
99. "Recycled Concrete Backfills Pipe". Highway \& Heavy Construction: Aug. 1984.

100. "Recycled Concrete, Dirty Words No Longer". Highway \& Heavy Construction; oct. 1988 ; vol. 103 No. io, p. 44-46.

101. "Recycled Rubble Saves Contractors Money". Roads \& Streets: Apr. 1973 ; p. 82-83.

102. "Recycling Concrete for Motorway Construction". Civil Engineering; March 1986; p. 55.

103. "Recycling of Residual Concrete". Betonwerk FertigteilTechnik; Dec. 1984; Vol. 50 No. 12, p. 830-836.

104. "Recycling Plant Crushes Big Paving Slabs". Highway \& Heavy Construction; July $1984 ;$ p. 34-35.

105. Recycling Portland cement Concrete; Federal Highway Administration; 1986 ; TD 2-40-47-5.

106. "Recycling Roads and Building with Portable Plants". Pit \&uarry; Feb. 1973; p. 91-92, 106.

107. "Recycling Rubble for Highway Purposes". Public Works; Oct. 1972 ; p. 87-88.

108. "Recycling of Building Rubbish and Preparation Plants". Aufbereitungstechnik; May 1986; Vol. 33 No. 5, p. 249255.

109. "Recycling Concrete for Asphalt Proves a Success". Highway \& Heavy Construction; Nov. 1987; p. 70-72.

110. Robertson, Joseph L. "Update on Recycling". Rock Products: June $1984 ;$ p. 25-27.

111. Roggenbuck, H.; Neumann, G.; Heide, W. "Total Renewal of Highway section with Complete Recycled of the Broke Up old Pavement Materials". Stresse und Autobahn; Apr. 1986; Vol. 37 No. 4, p. 131-139; ISSN: 0039-2162.

112. Rukavina; Mitchell. "Microwave Heating Recycles Hotmix Asphalt Paving". Rock Products; July 1989; p. 13.

113. Rukavina; Mitchell. "Producers Seek Recycle standard". Rock Products; Aug. $1987 ;$ p. 42 .

114. "Runway Concrete Recycled as cement Treated Base". Highway \& Heavy Construction; Feb. 1985; p. 34-35.

115. "Runway Concrete Recycled as Base and Aggregate". Highway \& Heavy Construction; Aug. 1986; p. 44-45. 
116. Saeys, Gorle, L. Dr. "Reuse of crushed Concrete as a Road Base Material". Demolition Methods and Practice; Nov. 1988 ; p. 736-745.

117. Samarai, Mufid A. "The Disintegration of Concrete Containing Sulphate-Contaminated Aggregates". Magazine of Concrete Research; Sept. 1976 ; vol. 28 No. 96, p. 130-

118. Schmidt, M.; Vogel, P. "Material Characteristics of Base Course Layers Containing Concrete and Asphalt Rubble". Strassen und Tiefbau; Feb. 1988; Vol. 42 No. 2, p. 19-25; ISSN : 0039-2197.

119. Schultz, R. "Concrete with Recycled Rubble Developments in West Germany". Demolition Methods and Practice; Nov. 1988 ; p. 500-509.

120. Schultz, R.R. "West Germany Must Learn from Long Experience". Building Research and Practice; May-June 1986; vol. 19 No. 3, P. 154-159; ISSN: 0182-3329.

121. Soshiroda, T. "To Take Care of what We Have Built with Limited Resources-Recycled Concrete". Shibaura Institute of Technology; 1983 ; p. 1-10.

122. Spencer, Robert. "Opportunities for Recycling $C \& D$ Debris". Biocycle; July 1990; Vol. 31 No. 7, p. 56-58; ISSN: 0276-5055.

123. "Spot Shortages Will Mean Expansion". Highway \& Heavy Construation; Sept. 1987; Vol. 130 No. 9, p. 66-69; ISSN: 0362-0506.

124. Stuttgart. Recycling concrete: Informationszentrum Raum U.; 1989 ; ISBN: 3-8167-3450-2.

125. Superfund Record of Decision: Priedman Property, NJ; Apri1 1985; PB85-232072. (EPA/ROD/RO2-85/013).

126. Superfund Record of Decision: New Lyme, OH; Sept. 1985; EPA/ROD/RO5/85/023.

127. Superfund Record of Decision: Schmalz Dump, wI; sept.

128. Superfund Record of Decision: Kummer Sanitary Landfill, WN: Sept. 1988; PB89-196786.

129. Suprenat, Bruce A.; Whelan, Michael. "Earthmoving and Heavy Equipment Proceedings". Equipment Requirements for Concrete Recycling; 1986 ; p. 52-64; ISSN: 0-87262-548-6. 
130. Swichkow, D. Superfund Record of Decision: Lake Sandy Jo, IN; Sept. 1986; EPA/ROD/RO5-86/043.

131. Takeda. "Demolition of Concrete structures". Demolition Methods and Practice; Nov. 1988; p. 41-48.

132. Teychenne, D.C. "Crushed Rock Aggregates in Concrete". Quarry Management; May 1978; p. 122-137.

133. Thomas, Craig O.; Thomas M.; Hover, Kenneth $c$. Wastepaper Fibers in Cementitious Composites; Feb. 1987; p. 16-31.

134. Trevorrow, A.; Joynes, H. Dr.; Wainwright, P.J. Dr. "Recycling of Concrete and Demolition waste in the U.K.". Demolition Methods and Practice; Nov. 1988 ; p. 520-526.

135. Turgeon, C.M., Research Project Engineer. Waste Tire and Shingle scrap Bituminous paving Test sections on the Munger Recreational Trail Gateway Segment; Feb. 1991; MN/RD/91/06.

136. "Urban Expressway Rebuilt on Recycled Concrete Base". ENG; Nov. $191979 ;$ p. 24-25.

137. "What Happens to Leftover Ready Mix?". Concrete Construction; March 1986; p. 299-305.

138. Willkomm, Wolfgang; Weber, Helmut. "Concrete Recycling". Strassen und Tiefbau; 1988 Vol. 42 No. 7-8, p. 11-15; ISSN : 0039-2197.

139. Wilson, D.G. "Demolition Wastes: Data Collection and Separation Studies". KIT; Dec. 1979.

140. Wilson, D.G.; Foley, P.; Wiesman, R.; Frondistou-Yannas, S. "Demolition Debris: Quantities, Composition and Possibilities for Recycling". Proceeding of the 5th Mineral Waste Utilization Symposium; April 13-14 1976; IIT Research Institute; Apr. 1976; p. 7-18.

141. Yamato, Takeshi; Emoto, Yukio; Soeda, Masashi; Sakamoto, Yoshifumi. "Some Properties of Recycled Aggregate Concrete".

142. Demolition Methods and Practice; Nov. 1988; p. 643-651. 
143. Yanagi, K.; Nakagawa, M. ; Hisaka, M. ; Kasai, X. "Effect of Impurities in Recycled Coarse Aggregate Upon a Few Properties of the Concrete Produced with it". Demolition Methods and Practice; Nov. 1988; p. 613-622.

144. Yoda, K.; Yoshikane, T.: Nakashima, Y.; Soshiroda, T. "Recycled Cement and Recycled Concrete in Japan". Demolition Methods and Practice; Nov. 1988 ; p. 527-536. 


\title{
APPENDIX A \\ BUMLARY OF QUEBTIONAAIRE
}

\begin{abstract}
Questionnaires were sent by Ken Hoover's office, of INDOT, to a total of 30 states. The states were selected by their similar characteristics of topography and/or climate. All together 22 states responded to the questionnaire, however some responded only by indicating that no recycling of concrete had taken place in that particular state. The following pages include a copy of the questionnaire and a summary of the pertinent comments and responses from 14 of the states which responded. All of the questionnaires have been kept with the references and can be obtained from Professors Scholer and Cohen's office at Purdue University.
\end{abstract}


Purdue University

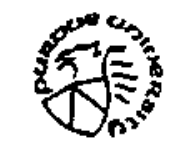

\section{QUESTIONNAIRE}

Uses of Recycled Concrete from Pavements and Building Rubble

GENERAL INFORMATION

Agency/Company Name

Address

Name of person filling out questionnaire (Mr./Ms)

Position(Title)

Date

Years dealing with Recycling Concrete

Enclosing additional information (YES/NO)

Please feel free to use additional paper if needed.

QUESTIONS

1) How do you determine whether to recycle or not?

2) What uses has your agency found for Concrete road and highway debris ?

a) Base material

b) Aggregate (concrete or asphait)

c) Others

Building rubble waste ?

a) Base material

b) Aggregate (concrete or asphalt)

c) Others

3) What portion of the fines left over from the crushing of PC. concrete are used in the final concrete mix and what does your agency do with the rest of the fines ? 
4) How does your agency judge the quality of the old material to be used in recycled concrete from roads and highways?

from building rubble?

5) What engineering properties have you found from concrete made with recycled concrete aggregates

Freeze Thaw ?

Strength 3 day 7 day 28 day Workability ? Water demand?

6) What changes are needed to make concrete with recycled aggregates equal in strength to concrete made with virgin aggregates ? (Cement content, Number of bags per mix, W/C ratio, Amount of fines from crushed concrete) Examples would be appreciated.

7) Have you found a relationship between strength of original concrete, used as the aggregate for the recycled concrete, and strength of the recycled concrete ?

8) Do you have a list of allowable percentages of contaminants in recycled concrete? Please list if available.

9) What do you feel is the minimum number of tons per year needed for recycling pavements rubble (ton/yr) and recycling building (ton/yr) to make it economical ? 
10) Does your agency find recycling economically feasible for Portland cements pavements ?

for building rubble ?

11) How does recycling compare with the cost of disposal ( unit costs of each and/or examples) ?

12) What methods does your agency use in recycling concrete for removal (Machine type, Crew size, etc.)

Crushing ?

Handling ?

Shipping ?

Storage?

Transportation ?

13) Do you have a cost break down for (\$/Ton) Crushing?

Handling ?

Shipping ?

Storage?

Transportation ?

(\$/Ton/Mile)

14) What type and quantity of production have you found realistic in recycling concrete (ton/day) and what is the yield of usable crushed material (ton/ton) ? 
15) What kinds of risks do you perceive are involved in using recycled concrete

Environmental ?

Structural ?

Liability ?

16) Have you recycled non air entrained concrete, d-cracked, or other problem pavements ? What was the outcome ?

17) Suggestions to Indiana ? 


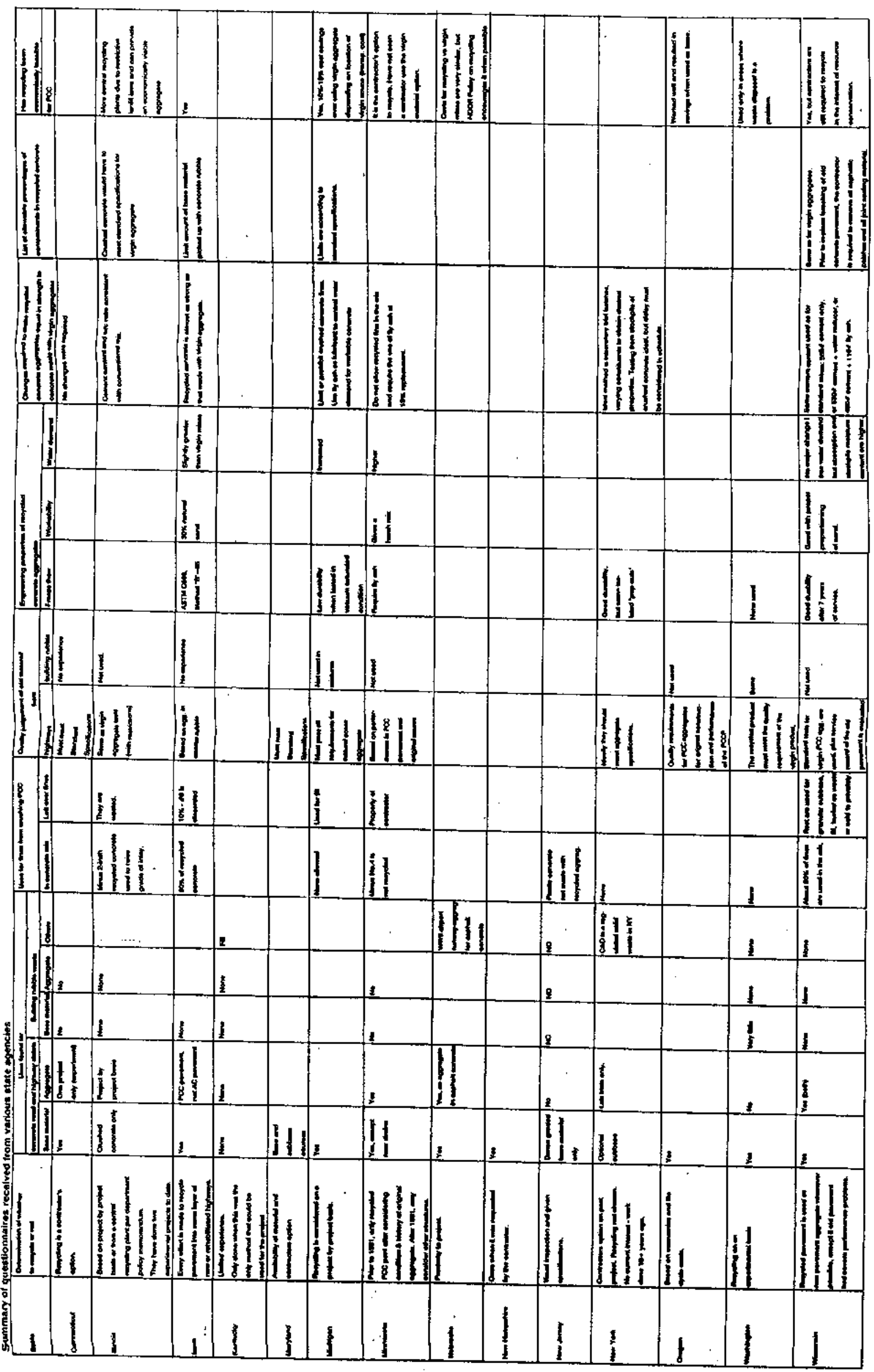




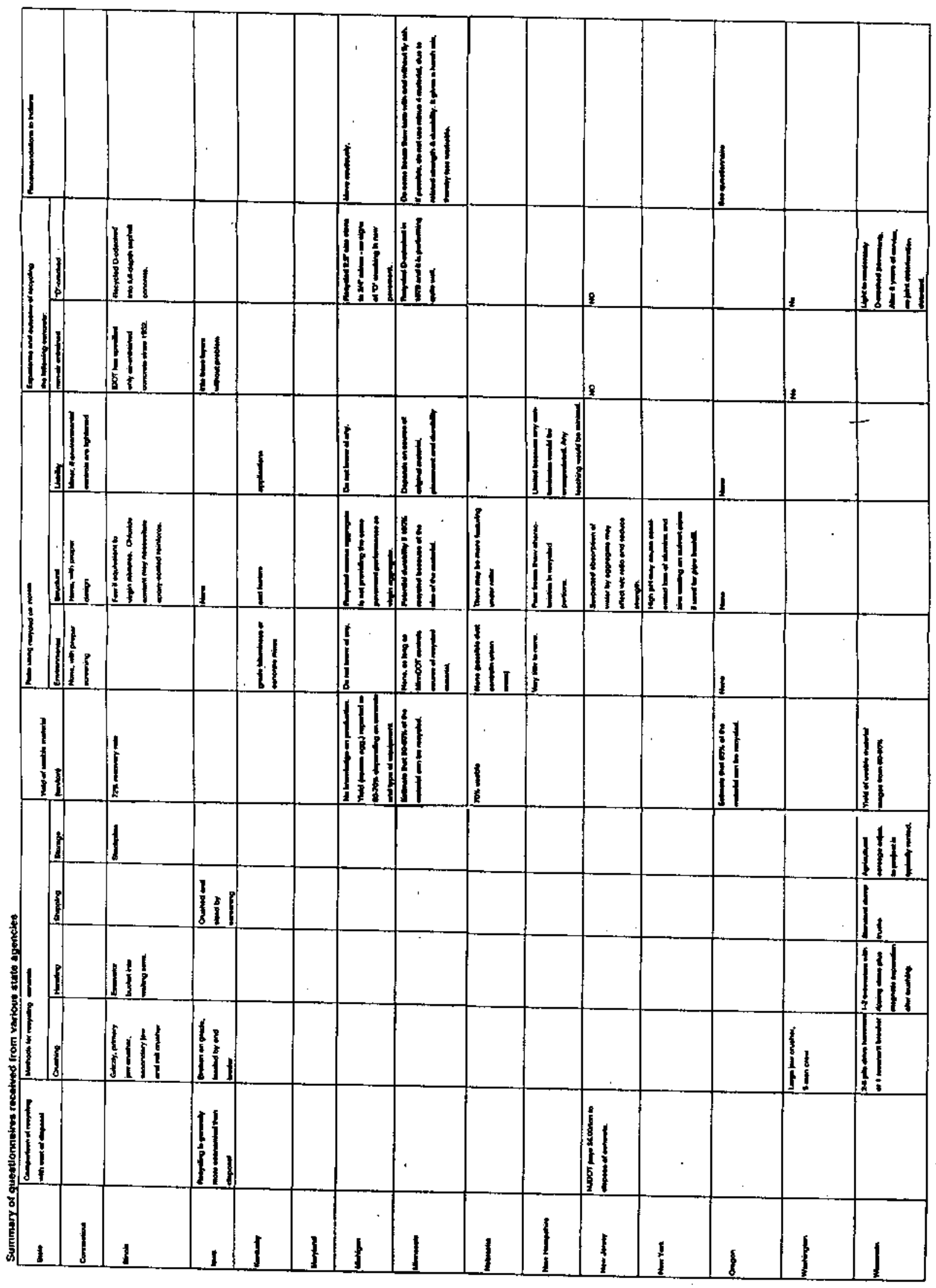

